\title{
Cosmogenic nuclide dating of two stacked ice masses: Ong Valley, Antarctica
}

Marie Bergelin ${ }^{1}$, Jaakko Putkonen ${ }^{1}$, Greg Balco ${ }^{2}$, Daniel Morgan ${ }^{3}$, Lee B. Corbett ${ }^{4}$ and Paul R. Bierman $^{4}$

$5 \quad{ }^{1}$ Harold Hamm School of Geology and Geological Engineering, University of North Dakota, Grand Forks, ND, 58202

${ }^{2}$ Berkeley Geochronology Center, Berkeley, CA

${ }^{3}$ Department of Earth and Environmental Science, Vanderbilt University, Nashville,

${ }^{4}$ Rubenstein School of the Environment and Natural Resources, University of Vermont/National Science Foundation Community Cosmogenic Facility.

Correspondence to: Marie Bergelin (marie.bergelin@und.edu)

\begin{abstract}
We collected a debris rich ice core from a buried ice mass in Ong Valley, located in Transantarctic mountains in Antarctica. We measured cosmogenic nuclide concentrations in quartz obtained from the ice core to determine the age of the buried ice mass and infer the processes responsible for the emplacement of the debris currently overlaying the ice. Such ice masses are valuable archives of paleoclimate proxies; however, the preservation of ice beyond 800 kyrs is rare and therefore much effort has been recently focused on finding ice that is older than $1 \mathrm{Ma}$. In Ong Valley, the large, buried ice mass has been previously dated at $>1.1 \mathrm{Ma}$. Here we provide a forward model that predicts the accumulation of the cosmic-ray produced nuclides ${ }^{10} \mathrm{Be},{ }^{21} \mathrm{Ne}$, and ${ }^{26} \mathrm{Al}$ in quartz in the englacial and supraglacial debris and compare the model predictions to measured nuclide concentrations in order to further constrain the age. Large downcore variation in measured cosmogenic nuclide concentrations suggests that the englacial debris is sourced both from subglacially-derived material and recycled

20 paleo surface debris that has experienced surface exposure prior to entrainment. We find that the upper section of the ice core is $2.95+0.18 /-0.22$ Myrs. The average ice sublimation rate during this time period is $22.86+0.10 /-0.09 \mathrm{~m} \mathrm{Myr}^{-1}$, and the surface erosion rate of the debris is $0.206+0.013 /-0.017 \mathrm{~m} \mathrm{Myr}^{-1}$. Burial dating of the recycled paleo surface debris suggests that the lower section of the ice core belongs to a separate, older ice mass which we estimate to be 4.3-5.1 Myrs old. The ages of these two stacked, separate ice masses can be directly related to glacial advances of the Antarctic ice sheet and potentially coincide with two major global glaciations during the early and late Pliocene epoch when global temperatures and $\mathrm{CO}_{2}$ were higher than present. These ancient ice masses represent new opportunities for gathering ancient climate information.
\end{abstract}


https://doi.org/10.5194/tc-2022-18

Preprint. Discussion started: 2 February 2022

(c) Author(s) 2022. CC BY 4.0 License.

(c) (i)

\section{Introduction}

Ice cores from glaciers and ice sheets are used as an archive for paleoclimate proxies, including: atmospheric gases, chemical compounds, and airborne particles (Dansgaard et al., 1969; Fredskild and Wagner, 1974; Castellano et al., 2004; Willerslev et al., 2007); however, the potential age of ice core records is limited by the fact that ice sheets are subject to deformation, ice flow, and basal melting. The oldest ice that has been recovered from the thickest parts of the Antarctic ice sheets is 800,000 years old (Jouzel et al., 2007). Although it is hypothesized that ice up to 1-1.5 Ma may also exist at great depth in the ice sheet (Fischer et al., 2013), recovering this ice would be a complex and costly endeavor. Therefore, we currently lack archives of climate information that extend beyond $\sim 0.8 \mathrm{Ma}$.

Bare ice is, in general, thermodynamically unstable under typical atmospheric pressure-temperature conditions and therefore prone to melt and/or sublimate. However, there exist regions of topographically constrained, extremely slow ice flow in which ice up to 2.7 Ma has been recovered near the surface (Yan et al., 2019). There are also several areas within the

40 Transantarctic Mountains where glacial ice is covered by supraglacial debris. A thick debris cover thermally insulates the ice surface and provides a physically plausible means of preserving near-surface ice for long periods. For example, Sugden et al. (1995) found glacier ice in Beacon Valley underlying a supraglacial debris containing an 8.1 Ma volcanic ash, leading them to conclude that the ice is older than 8.1 Ma. However, the antiquity of the Beacon Valley ice has been questioned on the basis of data suggesting that ice lost to sublimation is dynamically replaced by ice flow from upstream glaciers, resulting in a situation where relatively young ice underlies relatively old debris (Van Der Wateren and Hindmarsh, 1995; Ng et al., 2005; Hindmarsh et al., 1998; Stone et al., 2000). The lack of ice older than 1 Ma severely limits our direct paleoclimate record and creates uncertainties when modeling future climate predictions which include modeled configuration of the past Antarctica Ice Sheet (Bulthuis et al., 2019; Noble et al., 2020). This is particularly important during the Pliocene epoch (Dolan et al., 2018; Haywood et al., 2009), in which global surface temperatures and $\mathrm{CO}_{2}$ levels were higher than present (Pagani et al., 2010; Seki et al., 2010) and which is considered analog for current anthropogenic warming.

In Ong Valley, Miller Range, Transantarctic Mountains, a mass of glacier ice at least several tens of meters thick is found buried underneath $<1 \mathrm{~m}$ of supraglacial debris. Cosmogenic nuclide measurements from the supraglacial debris suggest an age of $>1.1 \mathrm{Ma}$, but most likely $>1.8 \mathrm{Ma}$ (Bibby et al., 2016). We collected a $944 \mathrm{~cm}$ long ice core from this buried ice mass and use concentrations of ${ }^{10} \mathrm{Be},{ }^{21} \mathrm{Ne}$, and ${ }^{26} \mathrm{Al}$ from the englacial debris to further constrain the age of the ice mass.

Our goal is to determine the age of the ice, understand its overall geologic history, and evaluate its potential use as a paleoclimate archive. We present a novel dating application of cosmogenic nuclides which aims to quantify a complex 
https://doi.org/10.5194/tc-2022-18

Preprint. Discussion started: 2 February 2022

(c) Author(s) 2022. CC BY 4.0 License.

(c) (1)

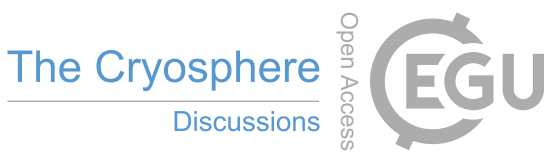

exposure history of this buried ice mass. By comparing measured cosmogenic nuclide concentrations from the englacial and

60 supraglacial debris with modeled concentrations, the nuclide inventory inherited from prior exposure can be distinguished from that produced after ice emplacement. We then apply a cosmogenic-nuclide burial dating method to the inherited inventory as an age constraint. We show that two sections of the ice core contain recycled surface debris that can be burialdated. The upper section is $\sim 3 \mathrm{Ma}$, which we interpret as the emplacement age of the bulk of the buried ice. The lower section has a significantly older burial age of $>4 \mathrm{Ma}$, and we interpret it as a portion of an older ice mass either in situ or

65 transported during emplacement of the younger ice.

\section{Study area}

Ong Valley is a $\sim 1.5 \mathrm{~km}$ wide and $\sim 7 \mathrm{~km}$ long glacial valley located in the Miller Range of the central Transantarctic Mountains, Antarctica $\left(83.25^{\circ} \mathrm{S}, 157.72^{\circ} \mathrm{E}\right)$. The current valley floor gradually rises from an elevation of $1500 \mathrm{~m}$ above sea level (masl) to 1700 masl at the valley head. Over the span of one year (2011), the recorded air temperature in the valley

70 ranged between $-49.0^{\circ} \mathrm{C}$ and $-4.0^{\circ} \mathrm{C}$, with mean of $-23.9^{\circ} \mathrm{C}$ (Bibby et al., 2016). In the head of the valley is a small alpine glacier, and the valley mouth is blocked by a $2 \mathrm{~km}$ wide exposed glacial ice front of the Argosy glacier (Fig. 1). 

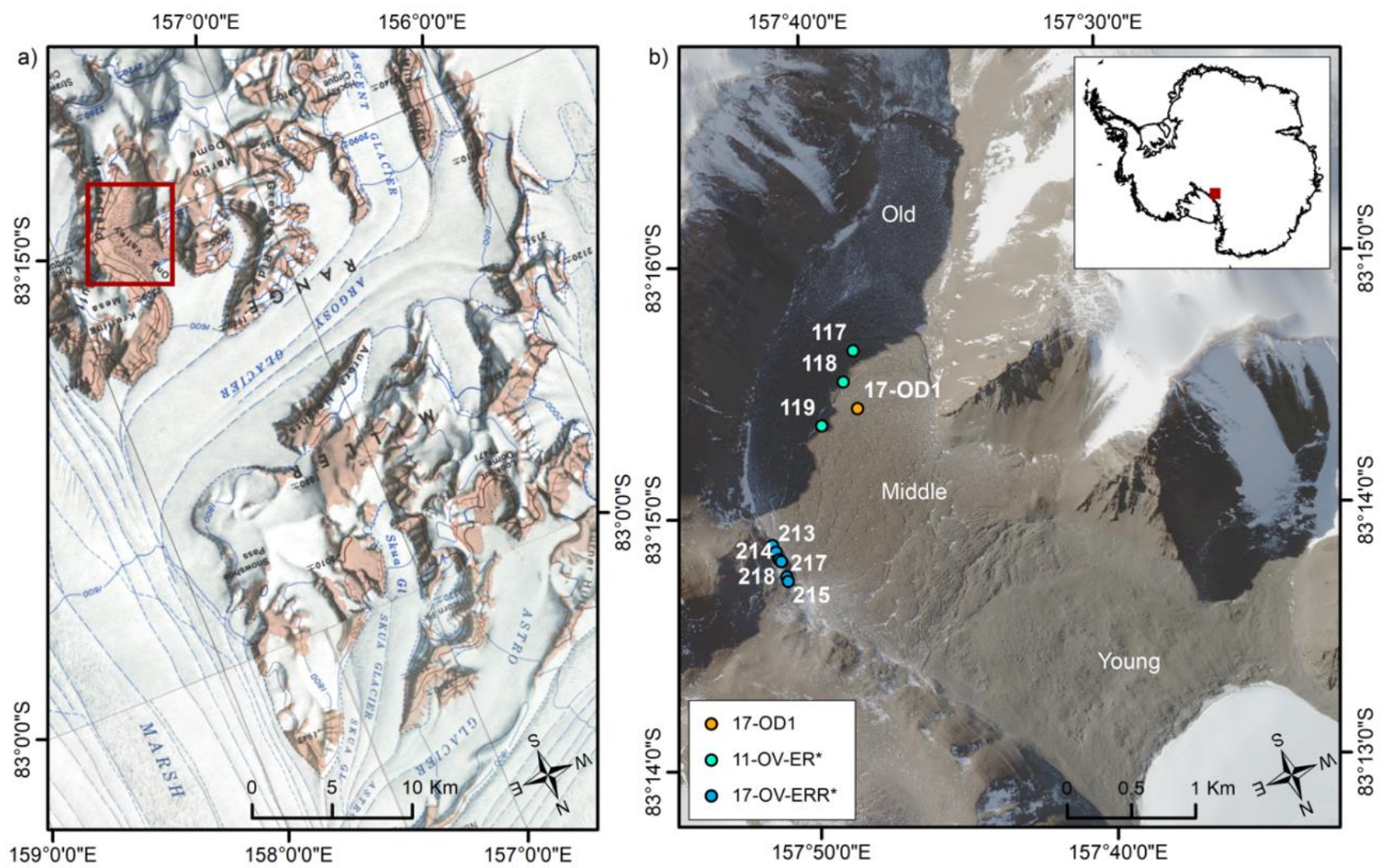

Figure 1 Location of Ong Valley. (a) Cropped USGS 1:250,000 scale topographic map of Miller Range, Antarctica, showing the location of Ong Valley. The red rectangle indicates the location of Ong Valley opening perpendicular to Argosy glacier. (b)

75 Worldview 2 satellite image of Ong Valley, Antarctica (@ 2016 Maxar). The dots indicate sampling sites for pit and ice core (orange), middle drift surface boulders (cyan), and lateral moraine boulders (blue). The legend shows the prefixes of sample names.

The valley floor is mostly covered by a well-developed and distinctive system of three glacial drifts; referred to as young, middle, and old (Bibby et al., 2016) (Fig. 1 and 2). These deposits were first described in 1975 and later identified as soil

80 chronosequences, increasing in age and maturity with distance from the Argosy glacier (Mayewski, 1975; Scarrow et al., 2014). Bibby et al. (2016) found that the three drift units were ablation tills formed by sublimation of debris-rich glacier ice that advanced into the valley. Eventually the ice became stagnant and began to sublimate, which led the englacial debris to accumulate on the surface as supraglacial debris. Although some of the supraglacial debris in Ong Valley could originate from a rockfall or colluvium from adjacent slopes, the drifts either have convex topography (middle and younger drifts) or

85 are bounded by prominent moraine ridges (older drift), and therefore significant input from local slopes is only possible immediately adjacent to valley walls. In addition, surfaces of active glaciers in the region uniformly lack significant surface 
sediment. While aeolian sediment transport onto the drifts is possible, drift surfaces are mainly composed of clasts and boulders too large for aeolian transport.
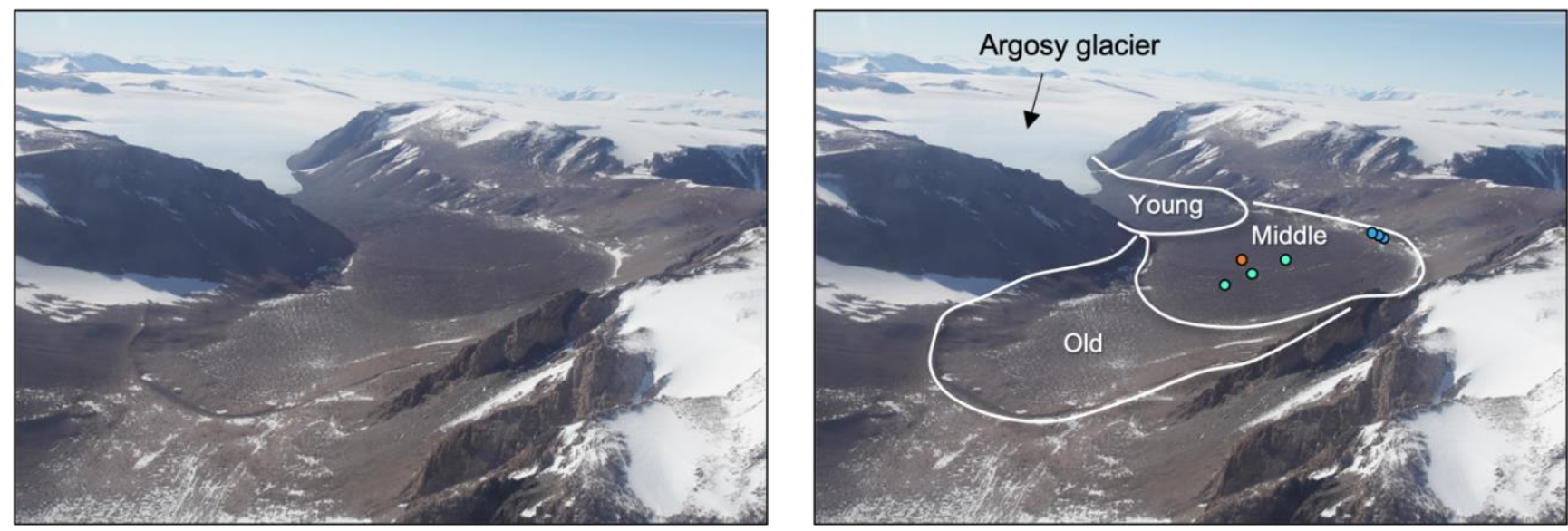

90 Figure 2 Oblique aerial photograph of Ong Valley (left) with added markings (right) indicating the young, middle, and old drifts (Bibby et al., 2016). The photograph is looking northward and down valley. The dots represent the sampling sites as identified in Fig. 1.

Exposure dating of the supraglacial debris from each drift has revealed the ages of 11-13kyr (young), >1.1 Myr (middle), and >2.7 Myr (old)(Bibby et al., 2016). The young and middle drift have buried ice under 0.1-0.5 m (young) and 0.6-0.8 m (middle) of loose supraglacial debris completely concealing the ice. In this paper we refer to the buried ice below the middle drift as the middle ice. Contrary, the oldest drift is devoid of buried ice, which, presumably, has sublimated over extended exposure (Bibby et al., 2016). The highest surface elevation of these buried ice masses in the valley is located on top of the middle drift and $\sim 200 \mathrm{~m}$ above the current Argosy glacier surface elevation at the valley mouth. Bibby et al. (2016) used cosmogenic-nuclide data from the surface debris layer to estimate that sublimation rates of $19-23 \mathrm{~m} \mathrm{Myr}^{-1}$ and surface erosion rates of 0.7-0.9 $\mathrm{m} \mathrm{Myr}^{-1}$ have persisted in the valley since deposition of the drifts. All three drifts have related lateral moraines on the valley walls that trace the original elevation of the ice surface. The oldest drift also has a distinct end moraine close to the head of the valley, which shows no signs of influence from the small alpine glacier currently located at the head of the valley.

105 Major and minor mineral analysis of englacial debris and the supraglacial debris from each of the three drifts display shared provenance that are significantly different from the local bedrock of Ong valley (Edwards et al., 2014; Morgan et al., 2020). The local bedrock is primarily dominated by Hope Granite and the Argosy Gneiss (Barrett et al., 1970). This indicates that these drifts were deposited by past advances of the Argosy glacier. 
https://doi.org/10.5194/tc-2022-18

Preprint. Discussion started: 2 February 2022

(c) Author(s) 2022. CC BY 4.0 License.

(c) (i)

\section{Cosmogenic-nuclide applications relevant for dating Ong Valley buried ice}

110 We use measured concentrations of cosmic-ray-produced nuclides in both the supraglacial debris covering the buried ice mass in Ong Valley and in debris within the buried ice in order to determine the age of the ice, its sublimation and erosion rate, and the geologic history of englacial debris. Cosmogenic nuclides are rare isotopes produced by cosmic-ray interactions with matter at Earth's surface (Dunai, 2010). Because the cosmic-ray flux is rapidly attenuated with depth below the surface, the concentration of cosmogenic nuclides can be used to date or quantify geologic processes that form or bury surface materials (Lal, 1991; Nishiizumi et al., 1993). For example, nuclide concentrations in rocks or sediment brought rapidly from depth to the surface and not subsequently disturbed can be interpreted as an "exposure age" for rock or sediment. If such material is then re-buried, the decay of cosmogenic radionuclides can be used to compute a "burial age". In general, given a set of assumptions derived from the geologic context of a sample, measured cosmogenic nuclide concentrations can yield information about the timing of geologic events or the rates of geologic processes such as erosion and sedimentation that have affected that sample.

There are three means by which we can apply cosmogenic-nuclide data to determine the age of the buried ice in Ong Valley. First, we can apply exposure-dating to the supraglacial debris; this approach was taken by Bibby et al. (2016). However, because the supraglacial debris is formed by sublimation after the deposition of glacial ice, the duration of the surficial exposure of the supraglacial debris is, by definition, less than the age of the ice. Thus, in this case, a surficial exposure-dating is expected to yield only a minimum age. We can exposure date the supraglacial debris by determining the apparent exposure age of the surface, defined as the exposure age calculated from a nuclide concentration with the assumption of a single period of exposure continuing until today without erosion or burial. The basic assumptions for such exposure dating are that a sample (i) have never been exposed to cosmic-rays prior to entrainment; (ii) have only been exposed to cosmic-rays since

130 deposition; and (iii) have then never been covered, displaced, nor disturbed while exposed at the surface. Further, we can use two nuclides to quantify both erosion and exposure time (Lal, 1991). The concentration of each nuclide is a function of exposure age and surface erosion rate. Therefore, measurements of both nuclides yield two independent equations in which both unknows can be solved for in certain circumstances.

135 The second approach that we use to determine the age of the buried ice mass is generally referred to as "depth-profile dating" (Hidy et al., 2010), and involves measurements of both surface and subsurface nuclide concentrations. This approach relies on the observation that surface concentrations show a greater dependence on sublimation and/or surface erosion rates and lesser dependence on emplacement age compared to concentrations in the subsurface below several meters depth (Stone et al., 1998; Braucher et al., 2009). Thus, paired subsurface and surface measurements can, in principle, yield a unique solution 
140 for both ice age and erosion rate. In Ong Valley, we apply this approach to both the supraglacial debris and subsurface englacial debris in core by creating a forward model that predicts nuclide concentrations at all depths as a function of the age of a deposit, the surface erosion rate of the deposit, and, in this case, the ice sublimation rate leading to formation of the supraglacial debris deposit. Fitting this forward model to a data set then yields best-fitting estimates of these input parameters.

The third approach can be used if any of the englacial debris has formerly been exposed at the Earth's surface and subsequently buried. Then we can apply a burial dating method based on the decay of cosmogenic radionuclides produced during the initial period of exposure. The principle of burial dating is that different cosmogenic nuclides, such as ${ }^{10} \mathrm{Be}$ and

${ }^{26} \mathrm{Al}$, in the same mineral are produced at a fixed ratio that depends on the production rates. Samples that have experienced a 150 single period of exposure at the surface have nuclide concentration ratios corresponding to the production ratio. If the two nuclides have different half-lives, burial of the sample to a depth at which the cosmic ray flux is diminished causes the observed ratio to change through time due to the different rates of radioactive decay (Lal, 1991). Thus, given several other assumptions, the ratio reflects the duration of burial. Although we had no prior reason to expect the englacial debris to be sourced from recycled surface debris, we show later that it is, in fact, the case in Ong Valley. Therefore, at our field site, burial dating can be used as an approach to constrain the age of the ice.

\section{Methods}

\subsection{Sample collection}

During the Austral summer, 2017/2018, we collected; (i) pit samples from unconsolidated supraglacial debris at drill site 17OD1, (ii) an ice core taken directly below the pit samples, and (iii) erratic boulders from other locations on the middle drift

160 surface and correlative lateral moraines (Fig. 1). The drill site OD1 was located at a central highpoint within the middle drift. We chose this site because any deformation of the buried ice should be minimized at this location, and colluvium and rockfall from the valley walls cannot reach the site. We determined the location and elevation of the core site using postprocessed differential GPS. Boulder samples were located using uncorrected handheld GPS and their elevations were checked against the Reference Elevation Model of Antarctica (REMA) Digital Elevation Model (DEM) (Howat et al., 2019).

165 Topographic shielding calculations for the sites follow Balco et al. (2008, with accompanying online material). 


\subsubsection{Vertical pit sampling of surficial regolith}

We excavated a hand dug pit for sampling the vertical section of the supraglacial debris (Fig. 3a). The pit was located in the center of a patterned ground polygon formation in which the surface did not show signs of reworking caused by former active polygon boundaries. The supraglacial debris is a sandy diamict with clasts of all sizes up to large boulders. The debris surface is covered by a lag deposit of clasts larger than approximately $5-10 \mathrm{~cm}$. The clasts are mostly angular with occasional faceted and/or weakly polished surfaces. Clast lithologies include both local bedrock and other rock types not locally present. The supraglacial debris shows no sign of stratification nor presence of ice cemented regolith and a sharp boundary can be observed between the debris and the underlying debris-rich ice mass (Fig. 3a).

a)

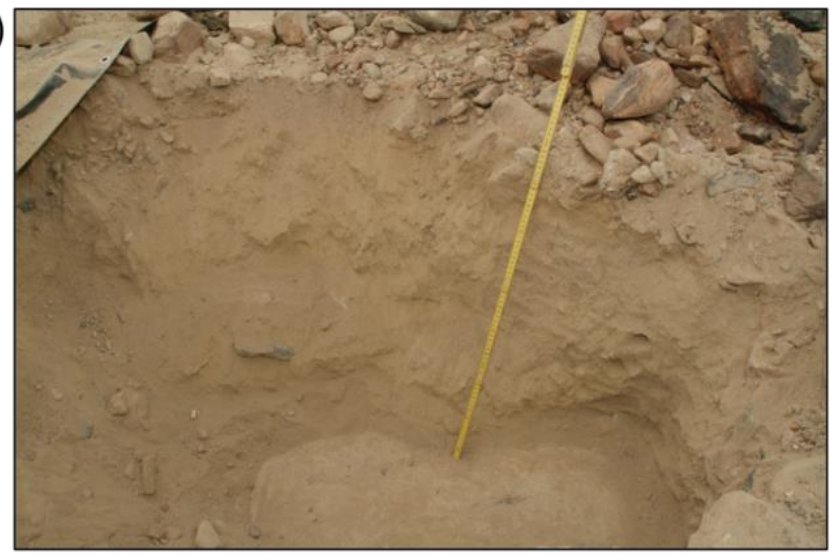

b)

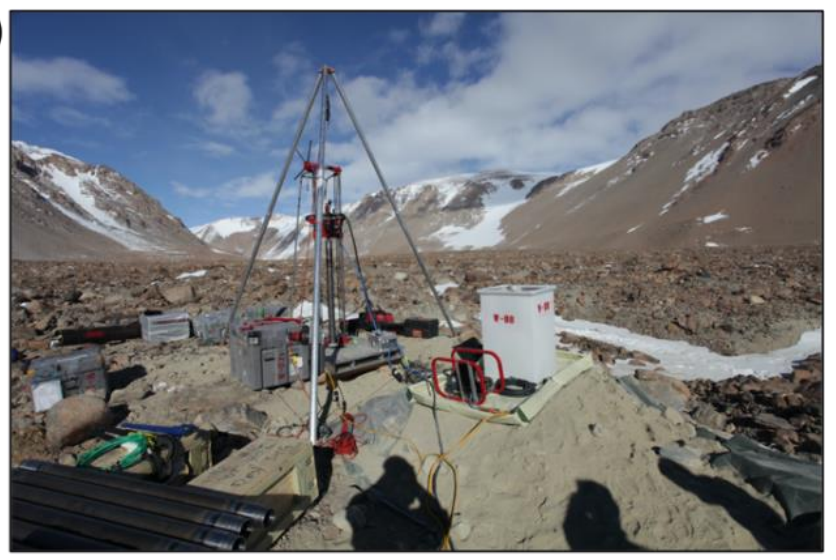

175 Figure 3 Photographs of the drill site 17-OD1. (a) excavated pit for sampling of the supraglacial debris. The middle drift ice surface is found at the bottom of the pit. The yellow ruler in the image measure $\sim 60 \mathrm{~cm}$ from the bottom of the pit to the surface of the supraglacial debris. (b) Winkie drill installed above the excavated pit for ice coring. Photograph looking south.

Bulk sediment samples spanning 3-8 $\mathrm{cm}$ in sample depth were collected at approximately $10 \mathrm{~cm}$ depth intervals (Table 1). A total of 6 samples were collected throughout the pit, from the surface to the ice/debris boundary. The depth of the pit is 62 $\mathrm{cm}$ reaching from the surface of the supraglacial debris down to the ice surface.

\subsubsection{Ice core sampling}

We collected a $944 \mathrm{~cm}$ long and $7 \mathrm{~cm}$ diameter vertical ice core directly below the deepest supraglacial debris sample. This allows us to construct a depth profile of cosmogenic nuclide concentrations extending from the surface of the supraglacial debris to the bottom of the ice core. An updated Winkie drill (Fig. 3b) was used for drilling in mixed-media ice (debris-rich ice) (Boeckmann et al., 2020). The recovered ice core was divided into segment lengths of $21 \mathrm{~cm}$ or less and stored frozen in individual watertight sample containers at the drill site. The samples were kept frozen at $<-20^{\circ} \mathrm{C}$ until processed in the geochemistry laboratory at University of North Dakota. 
https://doi.org/10.5194/tc-2022-18

Preprint. Discussion started: 2 February 2022

(c) Author(s) 2022. CC BY 4.0 License.

(c) (i)

\subsubsection{Sampling of middle drift boulders}

Samples of glacially transported boulders were collected during the 2011/12 field season (middle drift boulders) and the

190 2017/18 field season (lateral moraine boulders) (Fig. 4). Boulders were selected for sampling based on their evidence for stability in the drift. We preferentially selected boulders that were partially buried in supraglacial debris, and that otherwise showed no signs of overturning due to cryoturbation processes post-deposition. We also selected boulders that rose $>50 \mathrm{~cm}$ from the debris surface to limit burial by snow. For the middle drift samples (sample prefixes 11-OV-ER*, Fig. 1), we identified samples in the center of the valley to avoid any rockfall from the valley wall. For the lateral moraine boulders

195 (sample prefixes 17-OV-ERR*, Fig. 1) on the valley wall, we avoided rectangular boulders that were perched on the debris surface as these appeared to be jointed boulders more recently eroded out of the bedrock. At all sites, deeply weathered boulders were avoided in an attempt to limit samples with complex exposure histories. All boulders sampled were either granite or gneiss that contained a high percentage of quartz. With a hammer and chisel, we removed a 1-2 $\mathrm{kg}$ sample from the top of each boulder. GPS location, exposure geometry, and sample thickness were recorded. Boulders in the middle of the drift should provide minimum exposure ages for the middle drift as they were exposed as the middle ice has sublimated. 
https://doi.org/10.5194/tc-2022-18

Preprint. Discussion started: 2 February 2022

(C) Author(s) 2022. CC BY 4.0 License.

(c) a)

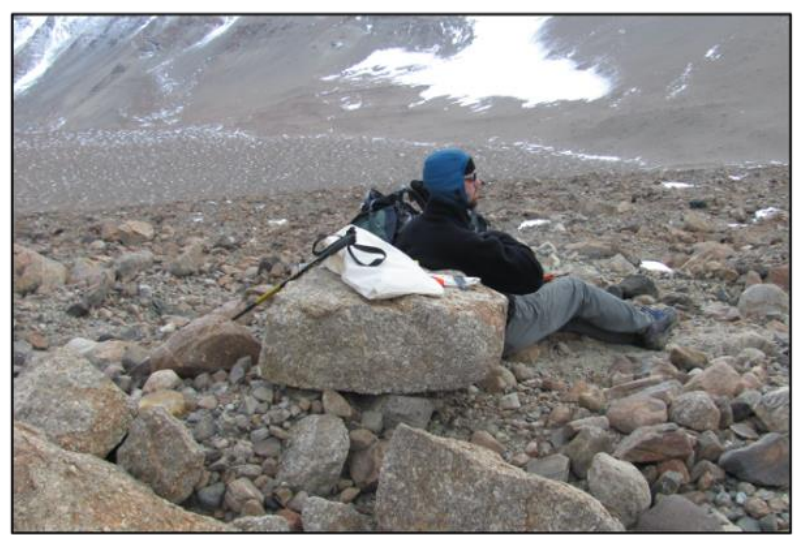

c)

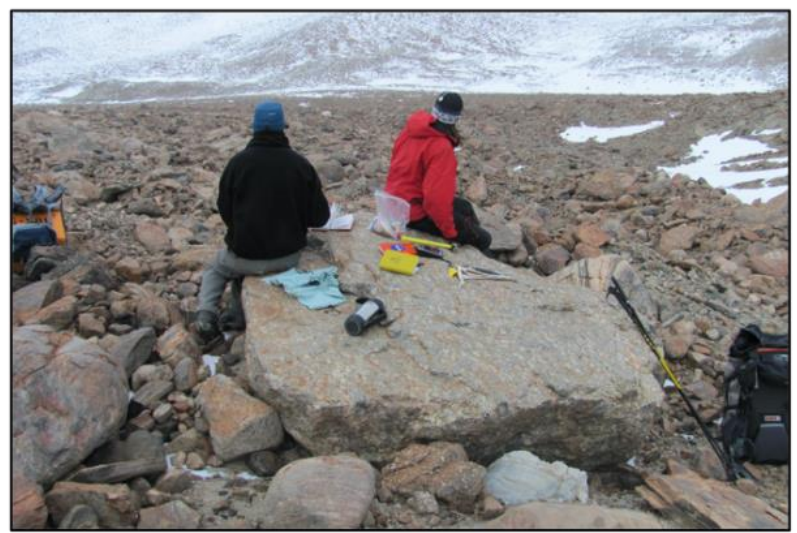

e)

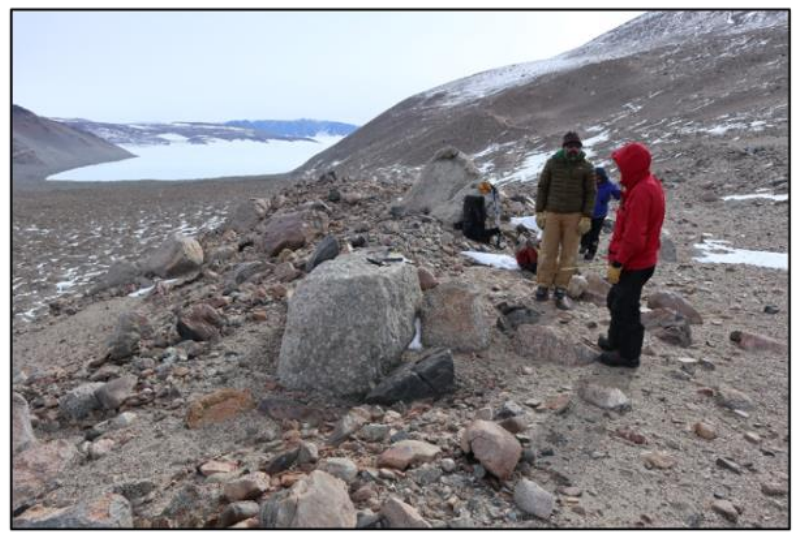

b)

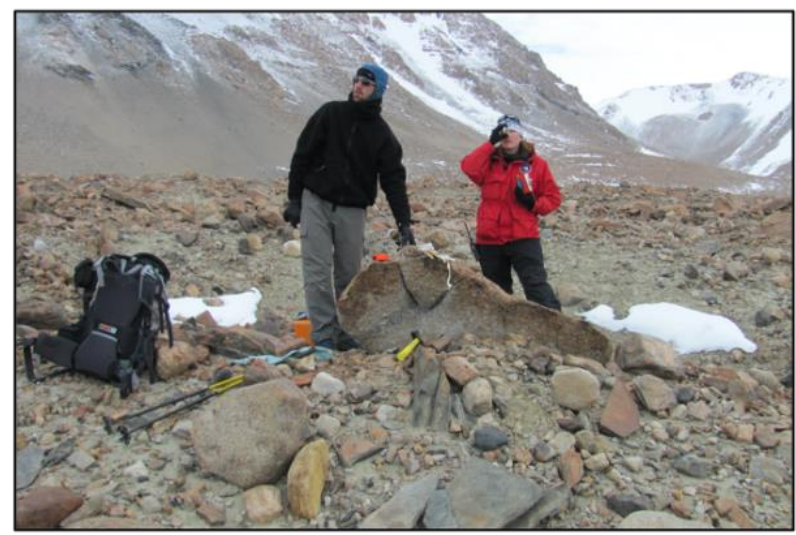

d)

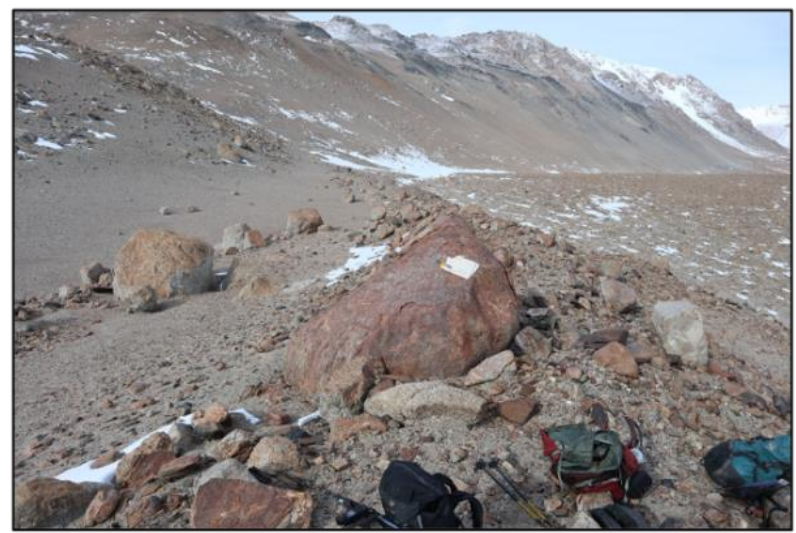

f)

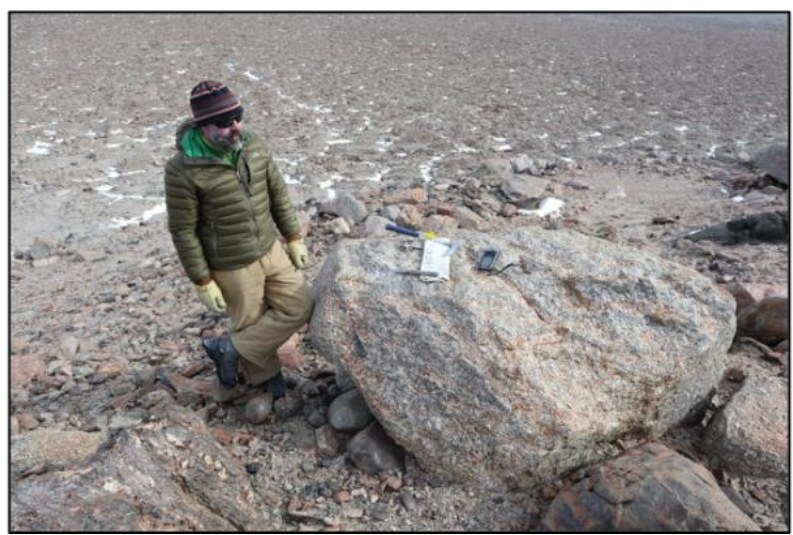

Figure 4 Photographs of surface boulders sampled from (a-c) the middle drift surface and (d-f) the East lateral moraine; (a) 11OV-ER-117，(b) 11-OV-ER-118，(c) 11-OV-ER-119，(d) 17-OV-ERR-213，(e) 17-OV-ERR-217， and (f) 17-OV-ERR-218. 
https://doi.org/10.5194/tc-2022-18

Preprint. Discussion started: 2 February 2022

(C) Author(s) 2022. CC BY 4.0 License.

(c) (i)

\subsection{Sample processing}

\section{4.2.1 Sample preparation}

Each ice core segment containing visible englacial debris was weighed before the ice was melted at room temperature. The liquid was then separated from the englacial debris, and the debris was oven dried at $\sim 70^{\circ} \mathrm{C}$. Then the samples were reweighed. Resulting masses of ice and debris in each core segment were then used to compute the density of the core using Eq. 4. Figure 5 shows pictures of the core and corresponding debris concentrations (blue) by weight as the function of depth.

210 The ice core alternates between sections of clean ice and debris rich ice with a maximum debris concentration of 0.57 by weight. Ice core segments with little or no debris were assumed to have the density of ice, $0.917 \mathrm{~g} \mathrm{~cm}^{-3}$. 
https://doi.org/10.5194/tc-2022-18

Preprint. Discussion started: 2 February 2022

(c) Author(s) 2022. CC BY 4.0 License.

(c) (1)
The Cryosphere

Discussions
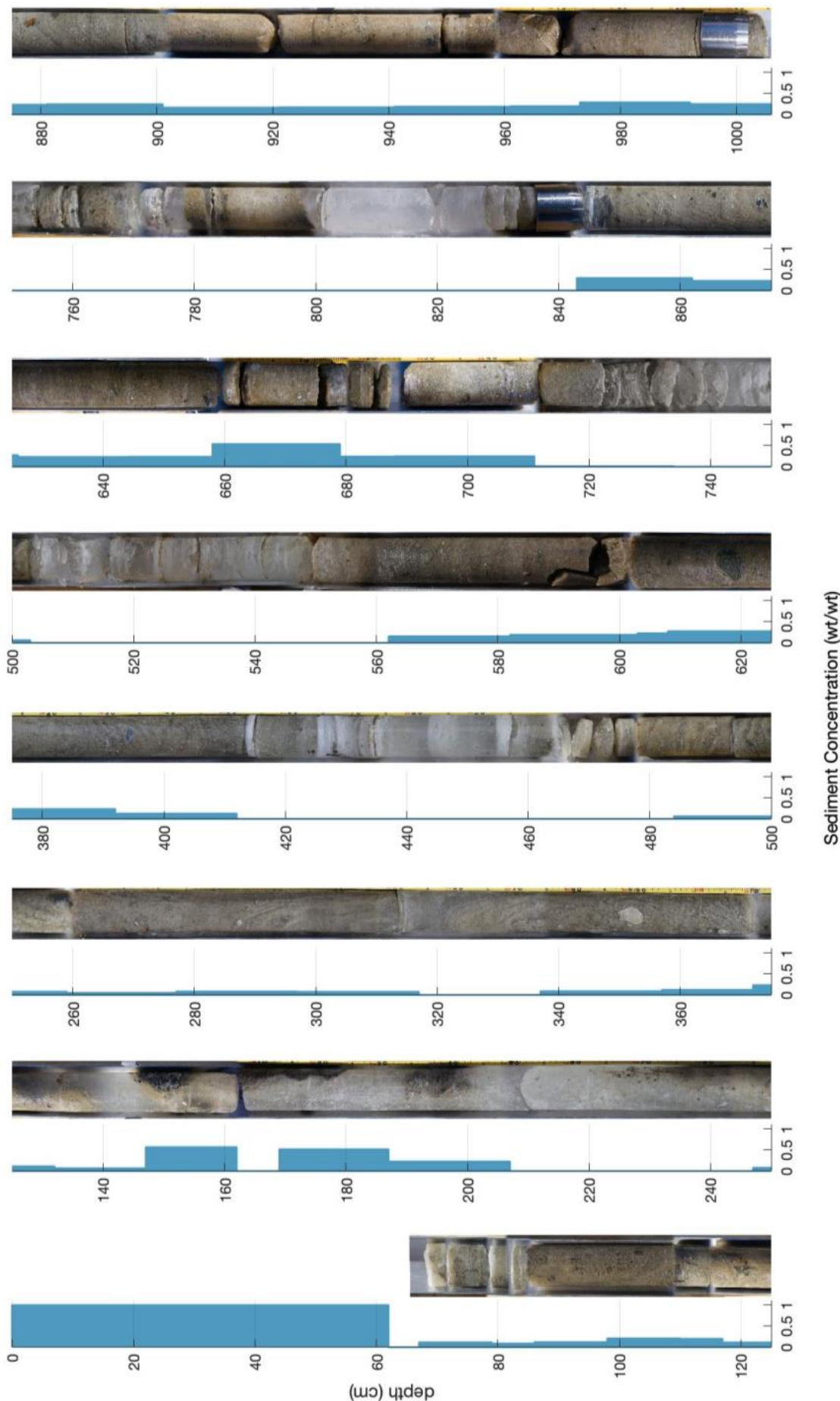

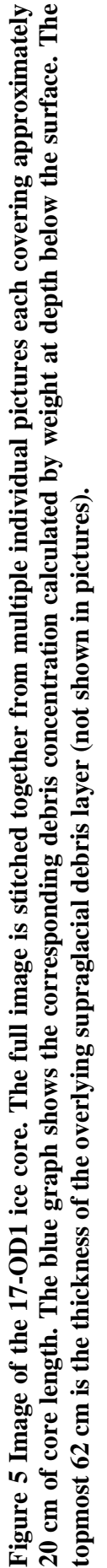

저 
https://doi.org/10.5194/tc-2022-18

Preprint. Discussion started: 2 February 2022

(c) Author(s) 2022. CC BY 4.0 License.

(c) (i)

The density of the supraglacial debris was measured by packing the sediment sample into a measuring cup of known volume and weighing it. This process was repeated five times for each sample to obtain a representative mean density of the supraglacial debris of $\sim 1.8 \mathrm{~g} \mathrm{~cm}^{-3}$, excluding grains $>2 \mathrm{~cm}$.

For cosmogenic nuclide analyses, the pit samples from the supraglacial debris were sieved to separate a grain size fraction of $250-500 \mathrm{~mm}$, and the englacial debris was sieved to a grain size of $250-833 \mathrm{~mm}$. This was done to maximize the amount of sample for cosmogenic nuclide analyses. Quartz grains were isolated and cleaned following the procedure described in Stone (2004). When needed, adjacent segments were merged so that enough quartz was available to permit precise beryllium (Be) and aluminum (Al) measurements (see Table 1 for details).

\subsubsection{Cosmogenic nuclide extraction and analysis}

After quartz preparation but prior to dissolution for Be-Al extraction, a $\sim 0.5 \mathrm{~g}$ aliquot of the prepared quartz was split off for

${ }^{21} \mathrm{Ne}$ measurements. These employed the "Ohio" noble gas mass spectrometer and extraction line at the Berkeley Geochronology Center (BGC). Details of neon (Ne) isotope measurements on this system are described in Balco and Shuster (2009) and Balter-Kennedy et al. (2020). ${ }^{21} \mathrm{Ne}$ concentrations in replicate analyses of the CRONUS-A intercomparison standard (Vermeesch et al., 2015) measured during analytical sessions in this study ranged from $314.3 \pm 9.4$ to $320.8 \pm 6.1$ Matoms $\mathrm{g}^{-1}$, indistinguishable from the accepted value of 320 Matoms $\mathrm{g}^{-1}$. In Tables 1 and 2, and in the supplement, we report ${ }^{21} \mathrm{Ne}$ concentrations as excess ${ }^{21} \mathrm{Ne}$ relative to atmospheric composition. Excess ${ }^{21} \mathrm{Ne}$ includes both cosmogenic ${ }^{21} \mathrm{Ne}$ and, potentially, nucleogenic ${ }^{21} \mathrm{Ne}$ derived from uranium (U) and thorium (Th) decay. $\mathrm{U}$ and $\mathrm{Th}$ concentrations in quartz from Ong Valley lithologies (Sams, 2016), expected Ne closure ages of these lithologies, and the observation that ${ }^{21} \mathrm{Ne}$ concentrations in drift and boulder samples from the youngest drift are significantly higher than expected for the last glacial maximum (LGM) age of that drift, all indicate that nucleogenic ${ }^{21} \mathrm{Ne}$ is significant in quartz in these lithologies. For samples

235 from supraglacial and englacial debris used to fit our forward model for nuclide accumulation, we did not make a correction for nucleogenic ${ }^{21} \mathrm{Ne}$ because it would be equivalent to inherited cosmogenic ${ }^{21} \mathrm{Ne}$ in our model simulations. Thus, such a correction would not affect values for ages or process rates inferred from the model simulations. In calculating exposure ages and erosion rates for boulder samples, we corrected for nucleogenic ${ }^{21} \mathrm{Ne}$ using an estimate of $7 \pm 3 \mathrm{Matoms} \mathrm{g}^{-1}$ obtained from ${ }^{21} \mathrm{Ne}$ data on boulders of similar lithology from the youngest drift (Sams, 2016). With this estimate, nucleogenic ${ }^{21} \mathrm{Ne}$ 240 comprises $2-7 \%$ of total excess ${ }^{21} \mathrm{Ne}$ in boulder samples. In addition, as discussed below, we applied this correction to subsurface samples used for burial dating. 
https://doi.org/10.5194/tc-2022-18

Preprint. Discussion started: 2 February 2022

(c) Author(s) 2022. CC BY 4.0 License.

(c) (i)

Chemical extraction and preparation of beryllium and aluminum from remaining quartz extracted from drill core samples were performed at the University of Vermont/National Science Foundation Community Cosmogenic Facility following the process described in Corbett et al. (2016). The pit and ice core samples were processed in two separate batches of 12 samples, in which each batch included a process blank and a standard. For all samples, $250 \mu \mathrm{g}{ }^{9} \mathrm{Be}$ was added with a beryl carrier made at the facility with a concentration of $291 \mu \mathrm{g} \mathrm{mL}-1$. In addition, a ${ }^{27} \mathrm{Al}$ carrier commercially available as an ICP standard from SPEX with a concentration of $1000 \mu \mathrm{g} \mathrm{mL}-1$ was added only to samples having < $1500 \mu \mathrm{g}$, of total Al. The amount of ${ }^{27} \mathrm{Al}$ carrier added was based on the total amount of native ${ }^{27} \mathrm{Al}$ in a sample quantified by Inductively Coupled Plasma Optical Emission Spectroscopy (ICP-OES) analysis. Quartz isolation and beryllium extraction for boulder samples followed the same procedure, except that three of the boulder samples $(11-\mathrm{OV}-\mathrm{ER}-117,118,119)$ were processed in chemistry laboratories at the Center for Accelerator Mass Spectrometry, Lawrence Livermore National Laboratory (LLNLCAMS).

255 Ratios of ${ }^{10} \mathrm{Be} /{ }^{9} \mathrm{Be}$ measured at Lawrence Livermore National Laboratory (LLNL) are normalized to the 07KNSTD3110 standard (Nishiizumi et al., 2007) with an assumed ${ }^{10} \mathrm{Be} /{ }^{9} \mathrm{Be}$ ratio of $2.85 \times 10^{-12}$. All ${ }^{26} \mathrm{Al} /{ }^{27} \mathrm{Al}$ ratios were measured at PRIME and normalized to the KNSTD-01-5-2 standard (Nishiizumi, 2004) with an assumed ${ }^{26} \mathrm{Al} /{ }^{27} \mathrm{Al}$ ratio of $1.818 \times 10^{-12}$.

Both ${ }^{10} \mathrm{Be}$ and ${ }^{26} \mathrm{Al}$ measurements were corrected for background using a procedural blank measured in each batch. Procedural blanks run with samples from the core site and were $14.9 \pm 3.3 \times 10^{3}$ and $49.8 \pm 9.4 \times 10^{3}$ atoms ${ }^{10} \mathrm{Be}$ and $259 \pm$ $45 \times 10^{3}$ and $37 \pm 20 \times 10^{3}$ atoms ${ }^{26} \mathrm{Al}$, and blanks run with boulder samples ranged from $24-109 \times 10^{3}$ atoms ${ }^{10} \mathrm{Be}$. For the majority of samples, blank corrections account for less than $1 \%$ of total ${ }^{10} \mathrm{Be}$ or ${ }^{26} \mathrm{Al}$ atoms present. The exception is several samples of englacial debris from the ice core, for which blank corrections were up to $4 \%$ of total ${ }^{26} \mathrm{Al}$ atoms present and up to $9 \%$ of total ${ }^{10} \mathrm{Be}$ atoms present. The reported uncertainty in the measured nuclide concentrations accounts for all sources

265 of analytical errors, including AMS measurement uncertainties, concentration measurement of ${ }^{10} \mathrm{Be}$ and ${ }^{26} \mathrm{Al}$, and procedural blanks. Measurement details appear in the Supplement.

\subsection{Forward Exposure model}

The exposure history of the middle drift in Ong Valley is complex, and the nuclide production cannot be accounted for by simply exposure-dating the supraglacial debris. Therefore, we apply a forward model which attempts to account for the geological processes that result in the thickening of the supraglacial debris and accumulation of cosmogenic nuclides at depth. As described in Bibby et al. (2016), the concentration of cosmogenic nuclides in the ice mass and the supraglacial debris is expected to result from a series of events: i) debris rich glacial ice was deposited into Ong Valley during glacial 
advancement, ii) the ice mass became stagnant and began to sublimate which caused the englacial debris to accumulate on the ice surface as a supraglacial debris layer; iii) as the ice continued to sublimate additional debris was added to the supraglacial debris layer from below, bringing deeper samples closer to the surface; iv) at the same time the supraglacial debris layer was subjected to surface erosion at a rate slower than the accumulation of debris from sublimation, such that the supraglacial debris thickness increased with time. The present-day thickness of the supraglacial debris layer is therefore a function of the age of ice emplacement, rate of ice sublimation, concentration of debris in ice, and rate of surface erosion. The numerical forward model attempts to account for the series of events listed above which lead to the cosmogenic nuclide concentrations measured today at depth below the surface in the middle ice. Input parameters to the model include the age of ice emplacement, the sublimation rate of the ice, and the surface erosion rate of the supraglacial debris layer. The model then predicts nuclide concentrations in supraglacial and englacial debris. By fitting the model to the observed nuclide concentrations, we obtain estimates for the age of the ice and for sublimation and erosion rates.

\subsubsection{Shielding Mass}

285 The production rate of cosmogenic nuclides at and below the surface is dependent on the shielding mass which attenuates the cosmic ray flux. The shielding mass is the cumulative mass of sediment and ice overlying each sample per unit area and has units of $\mathrm{g} \mathrm{cm}^{-2}$. It is equal to the product of the sample depth $(\mathrm{cm})$ and the mean density of the overlying material $\left(\mathrm{g} \mathrm{cm}^{-3}\right)$. The density is related to the concentration of the suspended debris $C_{D}$ and the ice $C_{I}$ in each core segment, and is calculated from the total segment weight, $\mathrm{M}_{\mathrm{t}}(\mathrm{g})$, and dried sediment weight, $\mathrm{M}_{\mathrm{s}}(\mathrm{g})$ such that,

$290 C_{D}=\frac{M_{s}}{M_{t}}$

$C_{I}=1-C_{D}$

The density of the ice core can then be calculated by mixing the two ice core components based on volume. Assuming the density of the ice $\rho_{I}$ to be $0.917 \mathrm{~g} \mathrm{~cm}^{-3}$ and the density of the debris $\rho_{D}$ to be that of rock, $2.68 \mathrm{~g} \mathrm{~cm}^{-3}$, for an ice core segment weight of $1 \mathrm{~g}$, the total weight of the ice core segment is then,

$295 M_{t}=C_{D}+C_{I}$

resulting in the density of the ice-debris mixture in an ice core segment $\rho_{M}$ to be,

$\rho_{M}=\frac{1}{\left(\frac{C_{D}}{\rho_{D}}\right)+\left(\frac{C_{I}}{\rho_{I}}\right)}$

\subsubsection{Depth as a function of time}

Once an ice mass with a mixture of ice and debris is emplaced at some time in the past defined as $\mathrm{T}(\mathrm{yr})$, the shielding mass above a given sample in the ice is decreasing through time at the rate determined by the sum of the sublimation rate of the 
ice and the surface erosion rate of the supraglacial debris. As the sample reaches the top of the ice, it becomes part of the

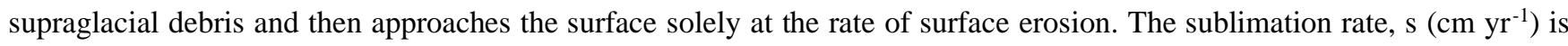
defined as a constant rate in which the surface of the ice-debris mixture (bottom of the supraglacial debris layer) is lowering. Note that this parameter represents a surface lowering rate due to sublimation and is not the same as a sublimation rate of pure ice as would be considered in a thermodynamics context. Therefore, the initial surface of the ice mass is $s T(\mathrm{~cm})$ above the present surface.

The rate at which mass is being lost by sublimation is the product of the sublimation rate and the density of the sublimating material. Since the ice mass consists of a mixture of ice and debris, only part of the ice mass is sublimating. The rate of mass loss associated with sublimation is given by $s\left(1-C_{D}\right) \rho_{M}\left(\mathrm{~g} \mathrm{~cm}^{-2} \mathrm{yr}^{-1}\right)$. While the ice is sublimating, the debris suspended in the ice mass is left behind on the ice surface and accumulating as supraglacial debris. The rate at which mass is added to the bottom of the supraglacial debris by sublimation is then, $s C_{D} \rho_{M}\left(\mathrm{~g} \mathrm{~cm}^{-2} \mathrm{yr}^{-1}\right)$. By assuming that at time of emplacement, the thickness of the supraglacial debris above the ice mass was zero, then with constant sublimation rate and erosion rate the total mass thickness of the supraglacial debris, $Z_{T}\left(\mathrm{~g} \mathrm{~cm}^{-2}\right)$ created by ice sublimation can be expressed as

$315 Z_{T}=T s C_{D} \rho_{M}-T E_{T}$

Where $\mathrm{T}$ is the age in years before present the ice was emplaced, and $E_{T}$ is the erosion rate expressed in mass units $\left(\mathrm{g} \mathrm{cm}^{-2}\right.$ $\mathrm{yr}^{-1}$ ). Equation (5) leads to the constraint that $s C_{D} \rho_{M}>E_{T}$, as the thickness of the supraglacial debris cannot be negative.

From field measurements, the thickness of the supraglacial debris is known to be $110 \mathrm{~g} \mathrm{~cm}^{-2}$ for 17-OD1-Pit2. Therefore, for any arbitrary values of age, sublimation rate, and erosion rate, the debris concentration must be chosen such that the measured supraglacial debris mass thickness is obtained after $T$ years. Assuming the ice mass mixture only consists of ice and debris, then the term $C_{D}$ and $\rho_{M}$ are different representations of the debris mass embedded in the sublimating ice.

Multiplying Eq. (4) with $C_{D}$, the debris concentration of the lost mass associated with sublimation can be solved,

$325 C_{D}=\frac{\rho_{D}\left(C_{D} \rho_{M}\right)}{\rho_{D} \rho_{I}-\left(\rho_{I}-\rho_{D}\right)\left(C_{D} \rho_{M}\right)}$

Equation (5) and (6) are two independent equations including the term $C_{D} \rho_{M}$. By isolating and substituting the term $C_{D} \rho_{M}$ in Eq. (5) into Eq. (6) the debris concentration now becomes independent of density of the ice core, and instead a function of sublimation rate $(s)$, erosion rate $\left(E_{T}\right)$ and age of ice emplacement $(T)$,

$C_{D}=\frac{\rho_{D}\left(\frac{Z_{T}+T E_{T}}{T S}\right)}{\rho_{D} \rho_{I}-\left(\rho_{I}-\rho_{D}\right)\left(\frac{Z_{T}+T E_{T}}{T S}\right)}$ 
https://doi.org/10.5194/tc-2022-18

Preprint. Discussion started: 2 February 2022

(c) Author(s) 2022. CC BY 4.0 License.

(c) (i)

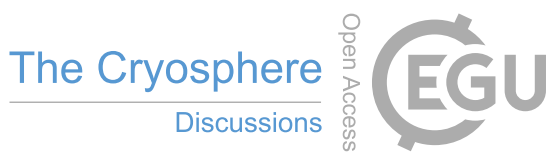

330 The debris concentration is constrained such that $0 \geq C_{D} \leq 1$. Further, Eq. (5) leads to the constraint that $s C_{D} \rho_{M}>E_{T}$, as the thickness of the supraglacial debris cannot be negative.

When predicting the concentration of cosmogenic nuclides, it is crucial to know a sample's depth at present, defined as $Z_{S, n o w}$ in units of mass depth $\left(\mathrm{g} \mathrm{cm}^{-2}\right)$, and its depth at some time, $\mathrm{t}(\mathrm{yr})$ in the past, $\mathrm{Z}(\mathrm{t})$. Since the samples collected consist of both

335 ice core samples and sediment from the above laying supraglacial debris, there are two separate cases of how a sample has approached the surface in the past.

In case 1, the sample is in the ice at present such that the sample depth is greater than the depth of the supraglacial debris, $Z_{s, n o w}>Z_{\text {till. }}$. From time of ice emplacement, the sample has then approached the surface at the rate of the ice sublimating and

340 the rate of surface erosion, such that

$z(t)=Z_{s, \text { now }}+t s\left(1-C_{D}\right) \rho_{M}+t E_{T}$

In case 2, the sample is in the supraglacial debris at present, such that $Z_{s, \text { now }}<Z_{\text {till. }}$ The time that the sample has been in the supraglacial debris is then defined as the mass height of the sample above the supraglacial debris base depth divided by the 345 rate of mass addition to the supraglacial debris,

$T_{\text {till }}=\frac{\left(z_{T}-Z_{S, \text { now }}\right)}{s C_{D} \rho_{M}}$

By the time of emplacement, the sample has then approached the surface in the same way as above. However, once the sample reaches the top of the ice and becomes part of the supraglacial debris, it approaches the surface at the rate of surface erosion only. This further allows for two scenarios to occur.

In case $2 \mathrm{a}$, if at time $t$ the sample is in the supraglacial debris, such that $t<T_{\text {till }}$, then

$z(t)=Z_{S, \text { now }}+t E_{T}$

In case $2 \mathrm{~b}$, if at time $t$, the sample is in the ice, where $t>T_{\text {till }}$, then

$355 z(t)=Z_{S, \text { now }}+T_{\text {till }} E_{T}+\left(t-T_{\text {till }}\right)\left(s\left(1-C_{D}\right) \rho_{M}+E_{T}\right)$

With this, it is now possible to calculate the depth of a sample at any given time in the past since the ice emplacement. This is needed in order to predict the total accumulation of nuclides in a sample, which is dependent on the nuclide production at depth. 
https://doi.org/10.5194/tc-2022-18

Preprint. Discussion started: 2 February 2022

(c) Author(s) 2022. CC BY 4.0 License.

(c) (i)

\subsubsection{Cosmogenic nuclide production at depth}

The cosmogenic nuclides ${ }^{10} \mathrm{Be},{ }^{26} \mathrm{Al}$, and ${ }^{21} \mathrm{Ne}$ are produced by high-energy spallation, negative muon capture, and fast muon interactions (Dunai, 2010). The high-energy spallation particles are likely to react with mass in the atmosphere and at Earth's surface. Therefore, the production of cosmogenic nuclides due to spallation reaction is highest at the surface and considerably decreases with depth. Muons are much less likely to interact with mass, and therefore travel farther below the surface before stopping (Lal, 1991). While cosmogenic nuclide production at depth below the surface is solely due to muon production, muons are responsible for less than $1 \%$ of the total production at the surface for all nuclides (Balco, 2017).

We calculated the ${ }^{10} \mathrm{Be}$ production rate using the 'LSDn' scaling method (Lifton et al., 2014) as implemented in version 3 of the online exposure age calculator originally described by Balco et al. (2008) and subsequently updated, and the CRONUSEarth "primary" calibration data set (Borchers et al., 2016). This yields a long-term (> $1 \mathrm{Ma}$ ) average production rate due to spallation of 25.3 atoms ${ }^{10} \mathrm{Be} \mathrm{g}^{-1}$ quartz $\mathrm{yr}^{-1}$. We then assumed that the ${ }^{21} \mathrm{Ne} /{ }^{10} \mathrm{Be}$ production ratio is 4.03 (Balco et al., 2019) and the ${ }^{26} \mathrm{Al} /{ }^{10} \mathrm{Be}$ production ratio is 6.75 (Balco et al., 2008).

The spallation production rate at the surface $P_{s p}(0)$ for a given cosmogenic nuclide decreases exponentially with depth (Lal, 375 1991), such that

$P_{s p}(z)=P_{s p}(0) e^{\left(\frac{-z}{\Lambda}\right)}$

Where $\mathrm{z}$ is the mass depth $\left(\mathrm{g} \mathrm{cm}^{-2}\right)$ and $\mathrm{L}$ is the attenuation length, defined as the distance where the energetic cosmic-ray flux intensity reduces by a factor of $e^{-1}$ due to scattering and absorption processes. The attenuation value varies depending on altitude and latitude and is taken to be $140 \mathrm{~g} \mathrm{~cm}^{-2}$ in Antarctica for ${ }^{10} \mathrm{Be},{ }^{26} \mathrm{Al}$, and ${ }^{21} \mathrm{Ne}$ (Borchers et al., 2016; Balco et al., 380 2019).

Muon production rates are not well approximated by a single exponential function. As depth increases, the energy of the remaining muons that have not yet stopped is higher, and therefore it takes proportionally longer for those to stop. The calculations of the production rates due to negative muon capture follows that of Heisinger et al. (2002a) and production 385 rates due to fast muon interactions according to Heisinger et al. (2002b) and are combined into a total muon production rate at depth, $P_{\mu}(z)$. The surface topography surrounding the sampling site also shields the samples of cosmic rays and will need to be accounted for when computing the production rate. This topographic shielding scaling factor $S_{G}$ is applied to the spallation and not the muon production rate (Balco et al., 2008). A topographic shielding of 0.993 was measured for drill site 17-OD1. The total production rate as function of depth can then be described as, 
https://doi.org/10.5194/tc-2022-18

Preprint. Discussion started: 2 February 2022

(c) Author(s) 2022. CC BY 4.0 License.

(c) (i)

In Fig. 6 we show the calculated changes in mass depth and production rate for a sample collected in the supraglacial debris $50 \mathrm{~cm}$ below the surface. The following arbitrary, but illustrative model parameter values are used for ice emplacement age, sublimation rates, and erosion rates: $1 \mathrm{Ma}, 20 \mathrm{~m} \mathrm{Myr}^{-1}$, and $0.1 \mathrm{~m} \mathrm{Myr}^{-1}$ respectively. The supraglacial debris thickness is that measured at drill site 17-OD1 and is $62 \mathrm{~cm}\left(110.15 \mathrm{~g} \mathrm{~cm}^{-2}\right)$. From the time of ice emplacement, a sample's depth has decreased linearly due to ice sublimation and surface erosion as the age of the ice increases, with a distinct change in rate once the sample exits the ice and becomes part of the supraglacial debris following that of Eq. (10) and Eq. (11). It is also observed that such samples experience great changes in nuclide production rates, following that of Eq. (13), from time of emplacement until present.

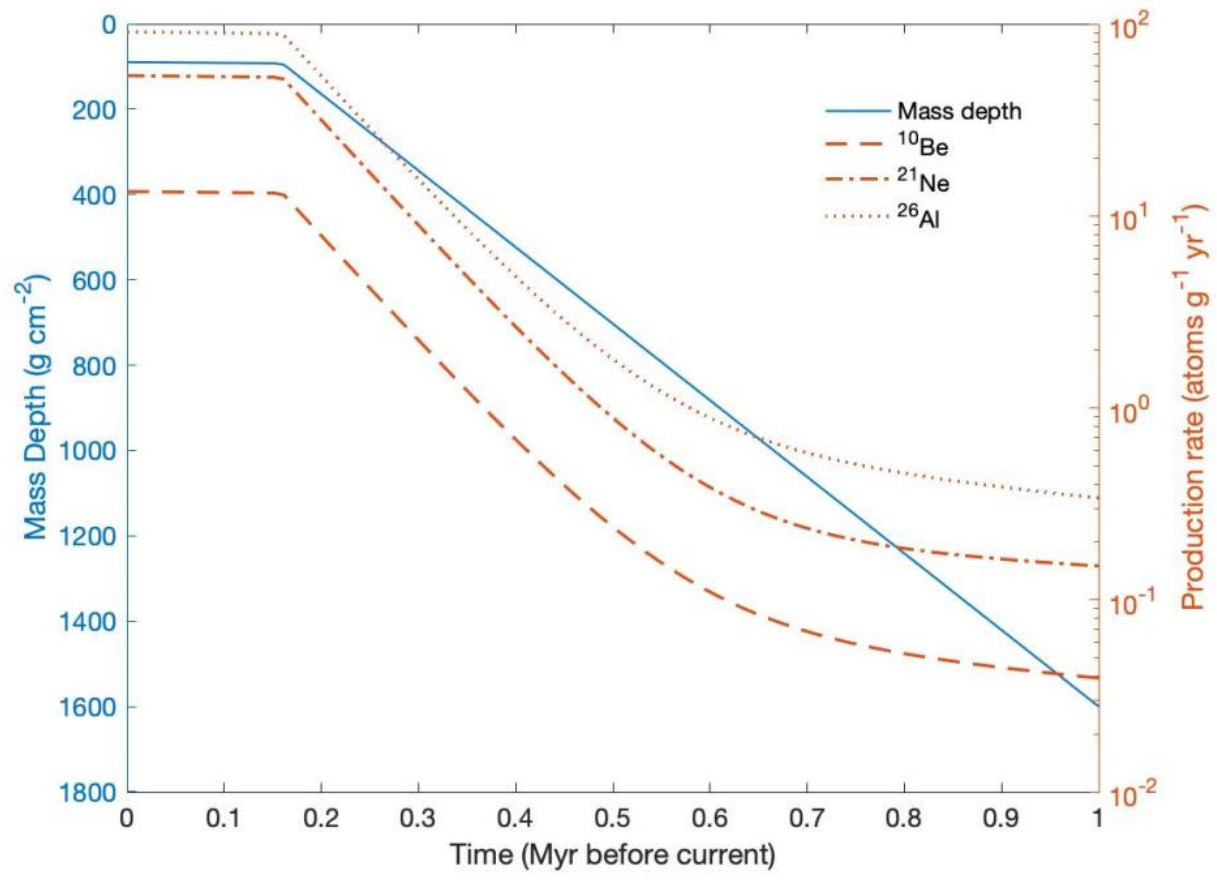

Figure 6 Graphical representation of the temporal change in mass depth (blue line) and production rates (orange lines) since ice emplacement for a sample found today at $90 \mathrm{~g} \mathrm{~cm}^{-2}(\sim 50 \mathrm{~cm}$ below the surface) in the supraglacial debris. Here, the given sample has an initial shielding mass of $1600 \mathrm{~g} \mathrm{~cm}^{-2}(\sim 14 \mathrm{~m})$ and approaches the surface at the combined rate of sublimation and erosion (Eq. 11). Once the sample reaches the ice surface it becomes part of the supraglacial debris ( 0.2 Ma) and approaches the surface solely at the rate of surface erosion (Eq. 10). As the sample's mass depth decreases it experiences considerable changes in production rates of cosmogenic nuclides (Eq. 13). The arbitrary model parameter values for these calculations are: 1 Ma ice emplacement, $20 \mathrm{~m} \mathrm{Myr}^{-1}$ sublimation rate, and $0.1 \mathrm{~m} \mathrm{Myr}^{-1}$ erosion rate. 


\subsubsection{Predicting cosmogenic nuclide concentration at depth}

When exposed to cosmic-rays, a sample will begin to accumulate cosmogenic nuclides over exposure time $T$, such that the total accumulation, $N$ (atoms $\mathrm{g}^{-1}$ ) in a subsurface sample at depth $z\left(\mathrm{~g} \mathrm{~cm}^{-2}\right)$ can be expressed as the integral of the production rate a sample undergoes from time of ice emplacement to the present. Since the exposure history of the englacial debris goes beyond the exposure history of the ice mass, some amount of inherited background nuclides $N_{\text {inh }}$ (atoms $\mathrm{g}^{-1}$ ) are present. While the concentration of the stable cosmogenic nuclide ${ }^{21} \mathrm{Ne}$ continues to build up, some of the unstable radionuclides, ${ }^{10} \mathrm{Be}$ and ${ }^{26} \mathrm{Al}$, are lost to radioactive decay. This is expressed as an exponential, such that the total number of cosmogenic radionuclides for a sample can be calculated using Eq. (14) and simplified to Eq. (15) for the stable nuclide ${ }^{21} \mathrm{Ne}$.

$N_{i}=N_{i, i n h} e^{\left(-\lambda_{i} T\right)}+\int_{0}^{T} P_{i}(z(t)) e^{\left(-\lambda_{i} t\right)} d t$

$N_{21}=N_{21, i n h}+\int_{0}^{T} P_{21}(z(t)) d t$

The subscript $i$ refers to the radionuclide of interest, ${ }^{10} \mathrm{Be}$ or ${ }^{26} \mathrm{Al}$, and $\lambda$ is the decay constant for the radionuclide $i$. The decay constants used in this paper are $4.99 \times 10^{-7}$ and $9.83 \times 10^{-7}$ for ${ }^{10} \mathrm{Be}$ and ${ }^{27} \mathrm{Al}$, respectively. We evaluate these integrals numerically using the default algorithm (integral) in MATLAB.

Given a set of environmental conditions; i) age of ice emplacement, ii) sublimation rate of ice, iii) surface erosion rate of the supraglacial debris, and iv) inherited nuclide concentration for each of the nuclides, as well as measurable site conditions (e.g., elevation and supraglacial debris thickness) Eq. (14) and Eq. (15) predicts the current total cosmogenic nuclide concentration in a sample at a unique depth $z$ at present time.

\subsubsection{Model fitting statistics}

We defined a misfit statistic to compare observed nuclide concentrations with those predicted by the model as the reduced $\chi^{2}$ statistic weighted by the relative uncertainty in measurements of all three nuclide concentrations in each sample. A best fit is found using the constrained nonlinear multivariable optimizing function (fmincon) in MATLAB while optimizing for the free parameters; (i) the age that the ice was emplaced, (ii) sublimation rate of the ice since emplacement, (iii) surface erosion rate of the accumulating supraglacial debris, and (iv) the inherited nuclide concentrations in the englacial debris at the time of ice emplacement.

Uncertainty distributions on the best-fit values of the model parameters are derived from a 10,000-iteration Monte Carlo simulation. Each Monte Carlo iteration draws from a set of normally distributed uncertainty for the measured nuclide concentrations and uses an initial guess for the free model parameters based on published values for the middle drift in Ong 
https://doi.org/10.5194/tc-2022-18

Preprint. Discussion started: 2 February 2022

(c) Author(s) 2022. CC BY 4.0 License.

(c) (i)

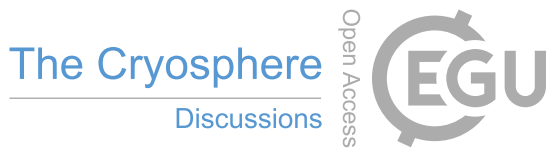

Valley (Bibby et al., 2016); 1.83 Ma ice emplacement age, $22.7 \mathrm{~m} \mathrm{Myr}^{-1}$ sublimation rate, $0.89 \mathrm{~m} \mathrm{Myr}^{-1}$ surface erosion rate, and inherited nuclide concentration of $0.14 \times 10^{6}$ atom $\mathrm{g}_{\mathrm{qtz}}{ }^{-1}, 11.4 \times 10^{6}$ atom $\mathrm{g}_{\mathrm{qtz}}{ }^{-1}$, and $0.82 \times 10^{6}$ atom $\mathrm{g}_{\mathrm{qtz}}{ }^{-1}$ for ${ }^{10} \mathrm{Be},{ }^{21} \mathrm{Ne}$, and ${ }^{26} \mathrm{Al}$, respectively. Although uncertainties in calculated nuclide production rates are similar in magnitude to the uncertainty measured in nuclide concentrations, they are not included in these results as all the samples are from the same location, and therefore must have the same surface production rate. Further, any of the Monte Carlo simulation results which did neither converge nor satisfy the optimization function evaluation or resulted in an ice emplacement age younger than the last glacial maximum (LGM) $(<20 \mathrm{ky})$ were excluded.

\section{Results}

\section{$445 \quad 5.1$ Ice core visual observations}

Visual inspection of the ice core indicate that it is primarily composed of debris-rich ice containing poorly sorted sediment ranging from clay to clasts exceeding the diameter of the borehole (Fig. 4). Bands of clean ice (lacking debris) were observed with a thickness $<0.5 \mathrm{~m}$. Sections of the debris-rich ice show distinct debris bands with a thickness of a few centimeters. The orientation of these debris bands is variable but commonly steeply dipping.

\subsection{Measured Ice Core Nuclide Concentrations}

We measured cosmogenic nuclide ${ }^{10} \mathrm{Be},{ }^{21} \mathrm{Ne}$, and ${ }^{26} \mathrm{Al}$ in 6 supraglacial debris pit samples (17-OD1-PIT2*) and 12 ice core samples (17-OD1-C1*). In addition, ${ }^{21} \mathrm{Ne}$ was measured for the surface sample (17-OD1-surf). The results show that cosmogenic nuclide concentrations in the englacial debris show large downcore variations (Table 1). The relative magnitude

of the variation is larger for ${ }^{10} \mathrm{Be}$ and ${ }^{21} \mathrm{Ne}$ than for ${ }^{26} \mathrm{Al}$, which indicates that the amount of time that has elapsed since ice emplacement is most likely on the order of several half-lives of ${ }^{26} \mathrm{Al}$ (the ${ }^{26} \mathrm{Al}$ half-life is $0.7 \mathrm{Ma}$ ). 
https://doi.org/10.5194/tc-2022-18

Preprint. Discussion started: 2 February 2022

(c) Author(s) 2022. CC BY 4.0 License.

The Cryosphere

Table 1 Measured cosmogenic nuclide concentrations in quartz extracted from supraglacial debris (prefix 17-OD1-surf/PIT2*) and ice core (prefix 17-OD1-C1*)

\begin{tabular}{|c|c|c|c|c|c|c|c|}
\hline Sample ID & $\begin{array}{l}\text { Top } \\
\text { depth } \\
\text { (cm) }\end{array}$ & $\begin{array}{l}\text { bottom } \\
\text { depth } \\
(\mathrm{cm})\end{array}$ & $\begin{array}{l}\text { Top } \\
\text { Mass } \\
\text { Depth } \\
\left(\mathrm{g} \mathrm{cm}^{-2}\right)\end{array}$ & $\begin{array}{l}\text { Bottom } \\
\text { Mass } \\
\text { Depth } \\
\left(\mathrm{g} \mathrm{cm}^{-2}\right)\end{array}$ & $\begin{array}{l}{ }^{10} \mathrm{Be} \times 10^{6} \\
\text { (atoms g-1 }{ }_{\mathrm{qtz}} \text { ) }\end{array}$ & $\begin{array}{l}{ }^{21} \mathrm{Ne} \times 10^{6} \\
\text { (atoms g-1 }{ }_{\mathrm{qtz}} \text { ) }\end{array}$ & $\begin{array}{l}{ }^{26} \mathrm{Al} \mathrm{x} 10^{6} \\
\left(\text { atoms g- }{ }_{\mathrm{qtz}} \text { ) }\right.\end{array}$ \\
\hline 17-OD1-surf & 0 & 1 & & & & $130.6 \pm 7.3$ & \\
\hline 17-OD1-PIT2-6-14 & 6 & 14 & 11.4 & 25.8 & $13.431 \pm 0.084$ & $109.1 \pm 6.2$ & $67.8 \pm 1.2$ \\
\hline 17-OD1-PIT2-14-17 & 14 & 17 & 25.8 & 31.1 & $13.512 \pm 0.085$ & $102.1 \pm 4.6$ & $67.3 \pm 1.4$ \\
\hline 17-OD1-PIT2-23-29 & 23 & 29 & 41.8 & 52.5 & $12.866 \pm 0.080$ & $104.9 \pm 5.8$ & $63.4 \pm 1.3$ \\
\hline 17-OD1-PIT2-37-43 & 37 & 43 & 66.7 & 77.4 & $11.593 \pm 0.070$ & $91.7 \pm 4.3$ & $58.2 \pm 1.2$ \\
\hline 17-OD1-PIT2-43-50 & 43 & 50 & 77.4 & 89.6 & $6.639 \pm 0.059$ & $55.2 \pm 2.8$ & $35.59 \pm 0.74$ \\
\hline 17-OD1-PIT2-56-62 & 56 & 62 & 99.9 & 110.2 & $4.246 \pm 0.052$ & $34.6 \pm 2.5$ & $23.32 \pm 0.53$ \\
\hline 17-OD1-C1-5-36 & 67 & 98 & 114.7 & 145.4 & $0.709 \pm 0.020$ & $11.4 \pm 1.5$ & $4.43 \pm 0.21$ \\
\hline 17-OD1-C1-36-48 & 98 & 110 & 145.4 & 158.2 & $0.573 \pm 0.014$ & $12.2 \pm 1.1$ & $3.44 \pm 0.15$ \\
\hline 17-OD1-C1-48-70 & 110 & 132 & 158.2 & 180.5 & $0.573 \pm 0.013$ & $13.3 \pm 2.9$ & $2.97 \pm 0.15$ \\
\hline 17-OD1-C1-70-100 & 132 & 162 & 180.5 & 216.9 & $1.459 \pm 0.030$ & $39.9 \pm 1.1$ & $4.22 \pm 0.22$ \\
\hline 17-OD1-C1-107-125 & 169 & 187 & 223.3 & 248.3 & $1.096 \pm 0.010$ & $37.3 \pm 5.8$ & $3.331 \pm 0.086$ \\
\hline 17-OD1-C1-125-145 & 187 & 207 & 248.3 & 269.9 & $0.871 \pm 0.017$ & $30.4 \pm 2.5$ & $2.83 \pm 0.10$ \\
\hline 17-OD1-C1-185-235 & 247 & 297 & 306.6 & 354.7 & $0.288 \pm 0.010$ & $14.0 \pm 2.8$ & $1.48 \pm 0.12$ \\
\hline 17-OD1-C1-235-310 & 297 & 372 & 354.7 & 426.9 & $0.1603 \pm 0.0090$ & $6.4 \pm 1.4$ & $1.17 \pm 0.10$ \\
\hline 17-OD1-C1-310-350 & 372 & 412 & 426.9 & 468.7 & $0.1161 \pm 0.0048$ & $9.2 \pm 5.7$ & $0.831 \pm 0.055$ \\
\hline 17-OD1-C1-500-582 & 562 & 644 & 607.0 & 694.5 & $0.1479 \pm 0.0041$ & $21.2 \pm 1.0$ & $0.450 \pm 0.040$ \\
\hline 17-OD1-C1-582-649 & 644 & 711 & 694.5 & 774.6 & $0.1323 \pm 0.0032$ & $28.3 \pm 7.4$ & $0.409 \pm 0.032$ \\
\hline 17-OD1-C1-781-819 & 843 & 881 & 895.8 & 938.1 & $0.4184 \pm 0.0081$ & $52.6 \pm 4.1$ & $0.489 \pm 0.034$ \\
\hline 17-OD1-C1-819-879 & 881 & 941 & 938.1 & 1001.2 & $0.516 \pm 0.010$ & $64.5 \pm 4.1$ & $0.49 \pm 0.031$ \\
\hline 17-OD1-C1-879-944 & 941 & 1006 & 1001.2 & 1071.7 & $0.4816 \pm 0.0091$ & $67.0 \pm 2.4$ & $0.471 \pm 0.038$ \\
\hline
\end{tabular}


https://doi.org/10.5194/tc-2022-18

Preprint. Discussion started: 2 February 2022

(C) Author(s) 2022. CC BY 4.0 License.

(c) (i)

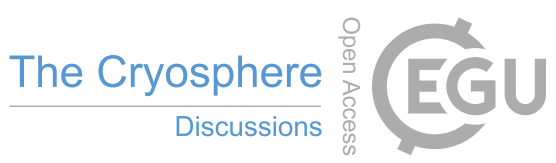

\subsection{Boulder surface exposure results}

We measured cosmogenic nuclide ${ }^{10} \mathrm{Be}$ and ${ }^{21} \mathrm{Ne}$ in quartz from erratic boulders from the middle drift surface and east lateral moraine (Fig. 1). Apparent ${ }^{10} \mathrm{Be}$ and ${ }^{21} \mathrm{Ne}$ exposure ages for the middle drift surface boulder samples are 1.55-2.16 Myrs and 0.82-1.39 Myrs for the East lateral moraine boulders (Table 2). Further, the apparent ${ }^{10} \mathrm{Be}$ exposure ages reported for all 465 boulder samples appear younger than of those from ${ }^{21} \mathrm{Ne}$, and is an indication that some process (e.g. erosion, burial, etc.) must have occurred which decreases the ${ }^{10} \mathrm{Be}$ nuclide concentration relative to ${ }^{21} \mathrm{Ne}$ 
https://doi.org/10.5194/tc-2022-18

Preprint. Discussion started: 2 February 2022

(c) Author(s) 2022. CC BY 4.0 License.

(c) (i)

\section{Model fitting}

470 In the following sections we first highlight several important features of the data from the ice core and supraglacial debris that we seek to explain using the forward model for nuclide accumulation described above. We then fit the forward model to the observations and thereby obtain estimates for the emplacement age and sublimation rate of the buried ice. Lastly, we calculate a minimum age for the middle drift in Ong Valley.

\subsection{Qualitative observations of the ice core data}

475 The forward model described in sect. 4.3.4 is an exposure model that is based on an assumption that the englacial debris is well mixed and therefore all the samples contain the same amount of inherited nuclides. The model calculates the postdepositional nuclide production during the exposure (Eq. 14 and 15). This is compatible with an ice mass that is emplaced during single glacial advance. After a single event of exposure, where sublimation and erosion has occurred, the concentration for a given cosmogenic nuclide in the englacial debris must decrease monotonically with depth as the production rate decreases with increased shielding mass.

However, multiple sections of the ice core show increase in cosmogenic nuclide concentration at depth (Table 1) and is therefore not compatible with a single exposure history described above. The most likely explanation for the observed increases in cosmogenic nuclide concentrations with depth in OD1 samples, is that englacial debris in various sections of the core have variable exposure histories prior to entrainment in the ice, and therefore have different inherited nuclide concentrations. Based on the measured nuclide concentrations we make the following two observations that guide our forward modeling.

The first observation is that the set of samples that display monotonically decreasing nuclide concentrations (Fig. 7. Sections

490 S1, E1 and E2) are segments of the ice core with relatively low debris concentrations. These samples follow the expectation of having an exposure history as outlined in the forward model. We define these samples to be of a low-nuclide concentration that is largely composed of subglacially derived material sourced from upstream of the Argosy Glacier and have minimal surface exposure prior to entrainment. The debris from such samples is therefore identified to be of 'englacial debris' (samples denoted englacial E1 and E2 and highlighted in blue in Fig. 7) including the current surface debris layer 495 (S1) that we assume has also originated from englacial debris. 

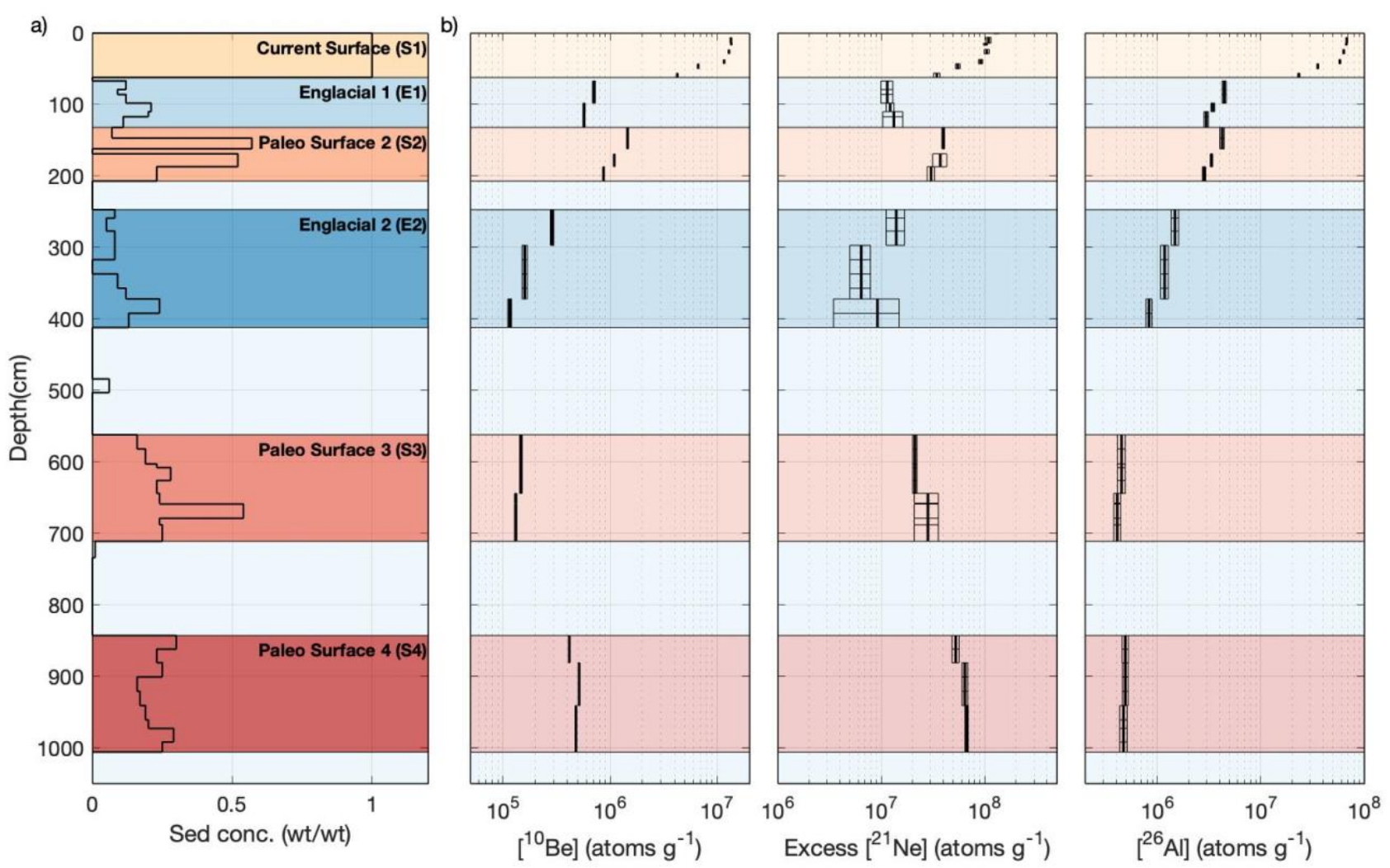

Figure 7 Depth plot of (a) sediment concentration (weight sediment/weight total sample) and (b) measured ${ }^{10} \mathrm{Be}$, ${ }^{26} \mathrm{Al}$, and ${ }^{21} \mathrm{Ne}$ nuclide concentrations. Color shades highlight the source of the debris. Yellow are current supraglacial debris samples (S1) and has same origin as blue samples (E1 and E2) identified as 'englacial debris' having no prior surface exposure before being subglacially entrained. Samples in shades of red is identified as 'paleo surfaces' (S2, S3, and S4) and to be of recycled surface debris that was exposed on the surface and entrained as the glacier overrode previously ice-free areas as it advanced into Ong Valley.

The second observation is that the debris-rich sections of the ice core (Fig. 7a. Sections S2, S3, and S4) have much higher nuclide concentrations and do not conform to the assumptions of a well-mixed ice mass containing subglacially derived debris and only experiencing in situ englacial accumulation of cosmogenic nuclides. We consider the debris in these sections to be from one or more high-concentration sources that are likely composed of material that was exposed for an extended period of time on the surface and entrained as the glacier overrode previously ice-free areas as it advanced into Ong Valley. In fact, these samples have ${ }^{21} \mathrm{Ne}$ concentrations similar to modern surface material (S1), and therefore must have been exposed for millions of years at or near surface. Therefore, debris from these subsurface samples having higher nuclide concentrations are identified as 'paleo surfaces' and is observed in three distinct units. Although these units must all contain 
https://doi.org/10.5194/tc-2022-18

Preprint. Discussion started: 2 February 2022

(c) Author(s) 2022. CC BY 4.0 License.

(c) (i)

some fraction of recycled surface debris, this may be of variable origin, so we identify these as S2, S3, and S4 (highlighted in shades of red in Fig. 7). In this paper we refer to this debris as recycled paleo surface.

Based on the above observations we can only explain a subset of the data with the forward model. However, the presence of

515 significant and variable inheritance in the debris from different sources suggests that we can apply a burial constraint to the inherited nuclide inventory having prior exposure. When fitting the model to the postdepositional nuclide inventory, this allows for an additional constraint on the age of ice emplacement.

\subsection{Forward modeling used to explain the data set}

520 The forward model predicts the accumulation of cosmogenic nuclides ${ }^{10} \mathrm{Be},{ }^{26} \mathrm{Al}$, and ${ }^{21} \mathrm{Ne}$ in the ice core and the overlaying supraglacial debris during a single event of exposure, constrained by following rates: sublimation of ice, surface erosion, and accumulation of supraglacial debris (Eq. 14 and Eq. 15). If we assume constant inheritance in the englacial debris, it is only possible to fit the model to the set of samples that show monotonically decreasing nuclide concentrations with depth. The model is therefore fitted to; i) surface sample in which only ${ }^{21} \mathrm{Ne}$ measurement is available, ii) all measured nuclide samples in the supraglacial debris, S1, and iii) samples of englacial debris, units E1 and E2.

While the recycled paleo surfaces S2, S3, and S4 are not included in the fitting of the forward model, they are utilized for burial-dating to further constrain the age of ice emplacement. The general idea for applying burial-dating to the recycled paleo surface samples is following. The high cosmogenic nuclide concentrations in the recycled paleo surfaces are the result of extended period of exposure of the debris prior to entrainment in the middle ice. The debris in these samples was part of a surface that was overridden during the latest advance of glacial ice into Ong Valley. Hence, this paleo surface debris must have been buried at the time the middle ice was deposited. The burial age obtained from burial-dating of the debris from these recycled paleo surface samples, should then reflect the timing of the middle ice emplacement. Further, the burial age of these samples cannot display ages that are younger than the event at which they got buried. Therefore, the minimum burial

535 age for any of the recycled paleo surface sections (S2-4) serves as the maximum age for when the middle ice was emplaced in Ong Valley.

Burial-dating of the recycled paleo surfaces is applied to their inherited nuclide concentrations. The inherited nuclide concentration is calculated by subtracting the modeled post-emplacement nuclide concentrations from the total measured nuclide concentrations. The apparent burial age of the recycled paleo surface debris is then determined from the nuclide ratio 
https://doi.org/10.5194/tc-2022-18

Preprint. Discussion started: 2 February 2022

(c) Author(s) 2022. CC BY 4.0 License.

(c) (i)

of the calculated inherited nuclide concentrations. The apparent burial age is the duration of burial inferred from a pair of nuclide measurements under the assumption that a sample has experienced a single period of exposure followed by a single period of burial. In reality, the sample could have experienced multiple shorter periods of burial; however, the calculated apparent burial age is the maximum single period a sample has been buried for. The age of ice emplacement for the middle

545 ice is then limited by the minimum apparent burial age for any of the recycled paleo surface samples S2-4. This constraint is incorporated into the model fitting such that when adding the nuclide concentrations lost by decay during burial, the nuclide ratio does not exceed that of the surface exposure production ratio. This burial constraint is applied only to the samples that are not used for forward model fitting, and that make up the recycled surface material S2, S3, and S4.

\subsection{Model Results}

550 By fitting the forward model prediction to measured nuclide concentrations from the englacial debris sample (S1, E1 and E2) and applying burial constraint to sections of recycled paleo surface debris (S2, S3 and S4), we are able to constrain the age of ice emplacement, sublimation rate, and surface erosion rate for the Ong Valley middle ice. The results of a 10,000-iteration Monte Carlo simulation provide an ice emplacement age of $2.95+0.18 /-0.22$ Myrs for the middle ice, with a best-fit, $\chi^{2}$ of $3.75+0.98 /-0.45$. The best-fitting sublimation rate since emplacement is $22.86+0.10 /-0.09 \mathrm{~m} \mathrm{Myr}^{-1}$, with a surface erosion rate of $0.206+0.013 /-0.017 \mathrm{~m} \mathrm{Myr}^{-1}$. The results of the simulation are not normally distributed, and the best-fit values are therefore reported as the $50^{\text {th }}$ percentile with error bounds given by the $16^{\text {th }}$ and $84^{\text {th }}$ percentile (Fig. 8 and Supplementary Figure). The inherited nuclide concentration for ${ }^{10} \mathrm{Be},{ }^{21} \mathrm{Ne}$, and ${ }^{26} \mathrm{Al}$ (the initial nuclide concentration present in the ice mass at the time of deposition $2.95 \mathrm{Ma}$ ago) is $0.101+0.018 /-0.017 \times 10^{6}$ atoms $\mathrm{g}^{-1}, 9.2+1.4 /-4.4 \times 10^{6}$ atoms g$^{-1}$, and 0.8249 $+0.0062 /-0.0031 \times 10^{6}$ atoms $\mathrm{g}^{-1}$, respectively. 
https://doi.org/10.5194/tc-2022-18

Preprint. Discussion started: 2 February 2022

(c) Author(s) 2022. CC BY 4.0 License.

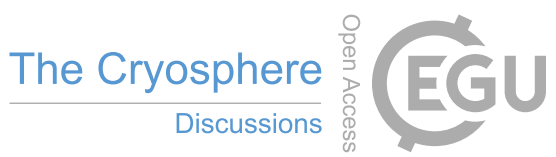
(c) (1)
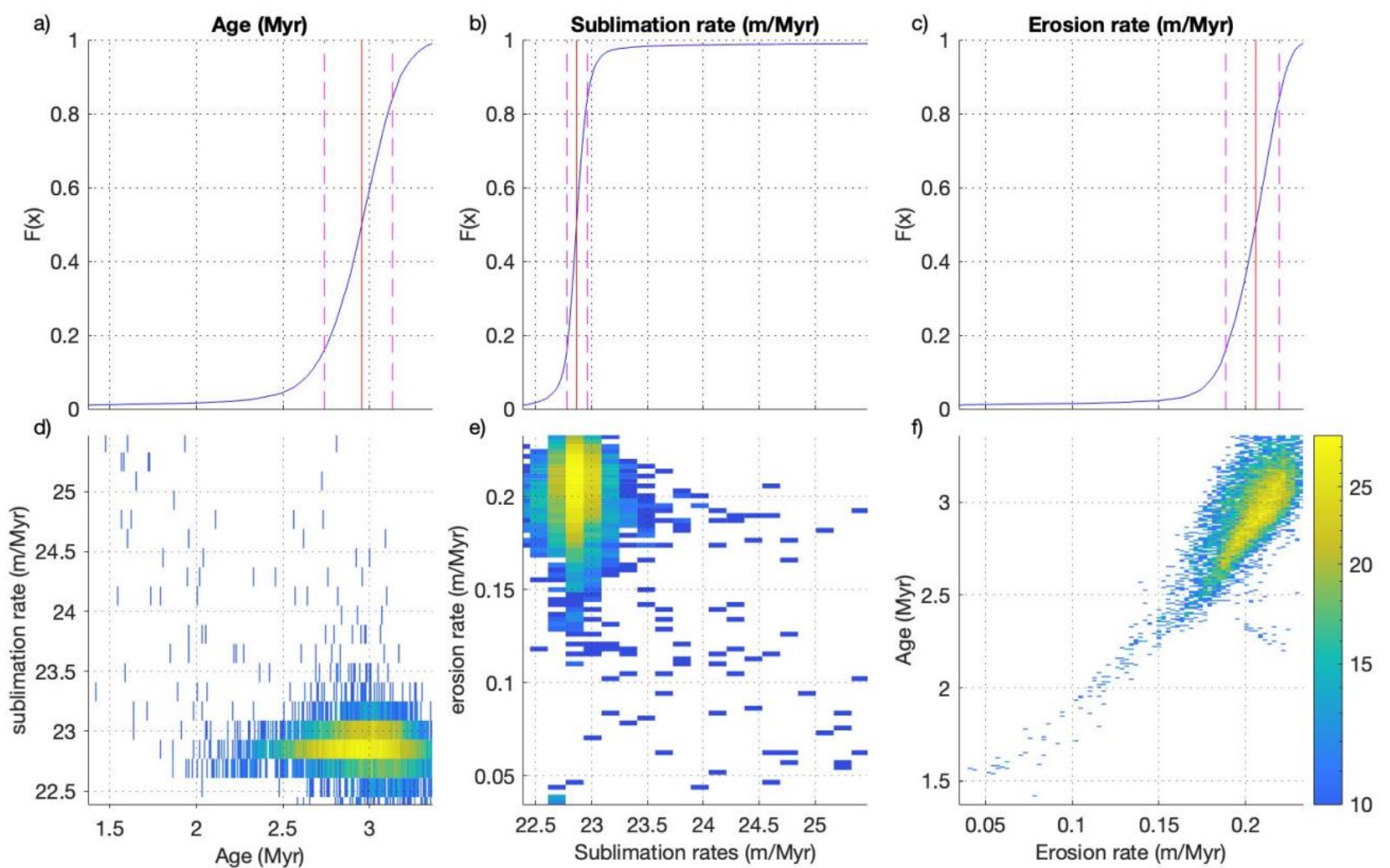

Figure 8 (a-c) Cumulative distribution of 10,000 fitted Monte Carlo simulation results showing the $50^{\text {th }}$ percentile (red line) with error bounds given by the $16^{\text {th }}$ and $84^{\text {th }}$ (pink lines). (f-e) Density plot as paired distribution of Monte Carlo simulation results separated into 1000 bins with yellow being high density and blue low density. Both the vertical and horizontal axes (d-f) are truncated to the $98 \%(0.01$ and 0.99$)$ confidence interval.

565 The measured debris concentrations in the ice segments range between 0 for clean ice and 0.57 for debris-rich ice, with an average of 0.13 by weight for the core. The average debris concentration for the best fit in the sublimated ice which produced the supraglacial debris over a period of $2.95 \mathrm{Ma}$ is $0.036-0.034$ by weight, and therefore an average ice-debris density of $\sim 0.931 \mathrm{~g} \mathrm{~cm}^{-3}$. Further, the resulting sublimation rate of $22.86 \mathrm{~m} \mathrm{Myr}^{-1}$ over the span of $2.95 \mathrm{Ma}$, results in a total ice surface lowering of $67.6 \mathrm{~m}$.

The model predicts nuclide concentrations at depth similar to those measured in the supraglacial debris (S1) and englacial debris (E1-2) and it is therefore evident that these units can be explained with the exposure model (Fig. 9a-c). Further, the paired-nuclide plot (Fig. 9d-f) clearly shows the distinction between the englacial debris data set (S1, E1-2) explainable by 
https://doi.org/10.5194/tc-2022-18

Preprint. Discussion started: 2 February 2022

(C) Author(s) 2022. CC BY 4.0 License.

(c) (i)

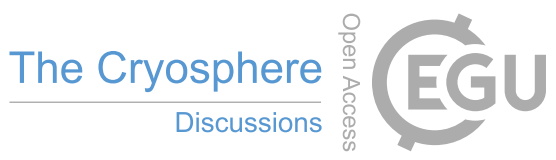

the model and the paleo surface samples (S2-4) having high nuclide concentrations and low paired-nuclide ratio, hence,

575 different origin which require the addition of a complex burial and exposure history.

Conceptually, higher nuclide concentrations require long surface exposure and any disequilibrium in the paired-nuclide ratio (ratio below the steady-state-erosion zone) is the effect of burial after exposure (Lal, 1991). However, the presence of a significant inherited nuclide inventory could result in surface and subsurface samples having ratios below the production 580 ratio and therefore indicating an apparent burial age. In Fig. 9d-f this is observed as both the predicted and all measured nuclide concentration ratios fall within the burial zone, and not near the steady-state-erosion zone. 
https://doi.org/10.5194/tc-2022-18

Preprint. Discussion started: 2 February 2022

(c) Author(s) 2022. CC BY 4.0 License.
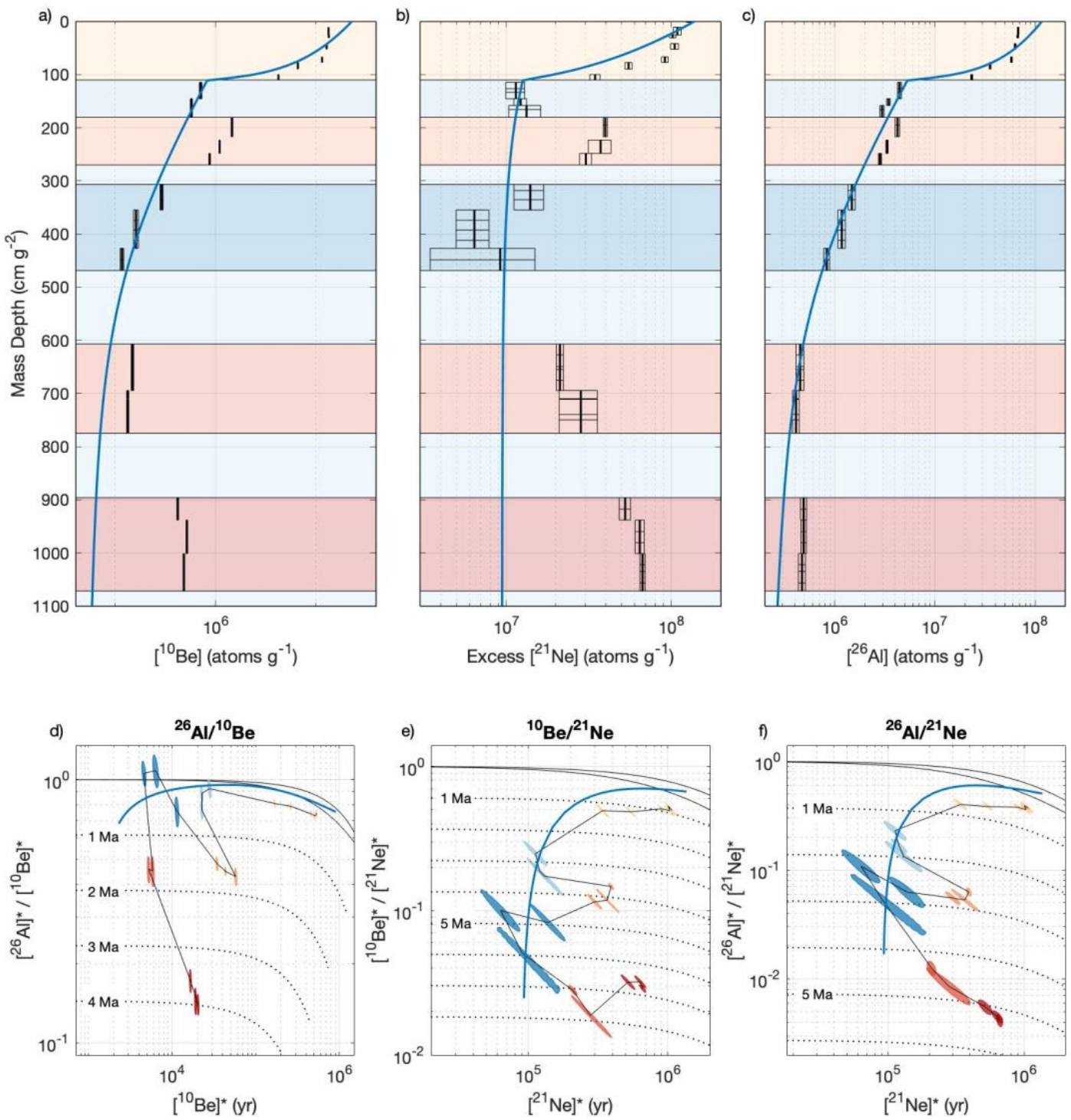

Figure 9 Measured and modeled cosmogenic nuclide concentrations as (a-c) mass depth below the surface for (a) ${ }^{10} \mathrm{Be}$, (b) ${ }^{21} \mathrm{Ne}$, and (c) ${ }^{26} \mathrm{Al}$, and (d-f) paired-nuclide exposure-burial diagram for (d) ${ }^{26} \mathrm{Al}-{ }^{10} \mathrm{Be}$, (e) ${ }^{10} \mathrm{Be}-{ }^{21} \mathrm{Ne}$, and (f) ${ }^{26} \mathrm{Al}-{ }^{21} \mathrm{Ne}$ pairs. Blue lines indicate the model predicted cosmogenic nuclide concentration from the pit surface to the bottom of the ice core. Colored boxes (ac) and sample colors (d-f) indicate debris source as detailed in Fig. 7. In (d-f), solid black lines show the steady-state erosion zone, and dashed lines show the burial lines as Million-year decay isochrons (See sect. 3 for more details). The measured nuclide concentration for each sample is represented by a shaded ellipse of its 1-sigma uncertainty. The black line connects the sample ellipses from the surface of the pit down to the bottom of the ice core. *Nuclide concentrations normalized to respective surface production rate. 
https://doi.org/10.5194/tc-2022-18

Preprint. Discussion started: 2 February 2022

(c) Author(s) 2022. CC BY 4.0 License.

(c) (i)

\subsection{Minimum exposure age}

595 We find the absolute minimum exposure age of the middle ice to be $1.331+0.020 /-0.024$ Ma, with a sublimation rate of $24.70+0.71 /-0.56 \mathrm{~m} \mathrm{Myr}^{-1}$. This age is derived from the minimum possible number of assumptions about the geologic history of the samples. For a surface sample, the apparent age is the calculated age from the measured nuclide concentration assuming a sample has experienced a single event of exposure, zero surface erosion, and no burial during that time period. Under such assumptions, a surface sample's apparent exposure age serves as the minimum exposure age. Therefore, the minimum age for the ice emplacement is obtained using the assumption that the inherited nuclide concentration for ${ }^{10} \mathrm{Be}$,

${ }^{21} \mathrm{Ne}$, and ${ }^{26} \mathrm{Al}$ is equal to the minimum concentrations measured throughout the core $\left(0.12 \times 10^{6}\right.$ atoms $\mathrm{g}^{-1}, 6.42 \times 10^{6}$ atoms $\mathrm{g}^{-1}$, and $0.41 \times 10^{6}$ atoms $\mathrm{g}^{-1}$, respectively) with zero surface erosion.

\subsection{Burial dating of Paleo Surface Debris}

As evident in Fig. 9, the paleo surface samples have elevated nuclide concentrations and do not fit our modeled predictions.

605 There is no scenario in which these samples can be explained solely by our forward exposure model which includes only sublimation and erosion. Therefore, these samples must have experienced significant periods of surface exposure prior to subglacial entrainment. Further, in order to have a lower paired-nuclide ratio than predicted (Fig. 9d-f), the samples must have experienced at least one period of burial. Hence, these observations were the reasons for the inclusion of burial-dating in our model.

610

Similar to the burial-dating constraint added to the forward model (sect. 6.2), we can determine the burial age of these paleo surface samples by first subtracting modeled postdepositional nuclide concentrations at the sample depths from the measured concentrations. This yields an estimate of the nuclide concentrations present in the paleo surface samples (S2-4) at the time they were buried, less the effect of subsequent radioactive decay. The choice to only fit the model to a subset of samples is

615 based on the assumption that the paleo surface samples have different geological history and thus different nuclide inheritance from that of the englacial debris (E1-2) samples. Therefore, the estimated inherited nuclide concentration for these paleo surfaces obtained from this subtraction is different from the inherited nuclide concentrations inferred from the model fitting. From these inherited nuclide concentrations in the paleo surface samples, we can then solve for the burial age which would cause a sample exposed at the surface (plotting on the simple exposure line) to have paired-nuclide ratios as

620 shown in Fig. 9. Uncertainties on the burial ages are derived from the same Monte Carlo simulation used to generate uncertainty estimates for the model parameters. 
The burial ages for the three paired-nuclide ratios, ${ }^{26} \mathrm{Al} /{ }^{10} \mathrm{Be},{ }^{10} \mathrm{Be} /{ }^{21} \mathrm{Ne}$, and ${ }^{26} \mathrm{Al} /{ }^{21} \mathrm{Ne}$ for $\mathrm{S} 2$ are $3.21 \pm 0.20 \mathrm{Myr}, 4.20 \pm$ $0.27 \mathrm{Myr}$, and $3.69 \pm 0.21 \mathrm{Myr}$, respectively. The paleo surface S3 and S4 indicate longer periods of burial, with S3 have burial age of $4.33 \pm 1.00 \mathrm{Myr}, 7.58 \pm 0.61 \mathrm{Myr}$, and $6.24 \pm 1.35 \mathrm{Myr}$, and S4 has burial ages of 5.06 $\pm 0.25 \mathrm{Myr}, 6.61 \pm 0.12$ Myr, and $5.78 \pm 0.15 \mathrm{Myr}$, respectively for each of the three nuclide pairs. Figure 10 shows the paired nuclide ratios for each of the paleo surfaces as their apparent burial ages.
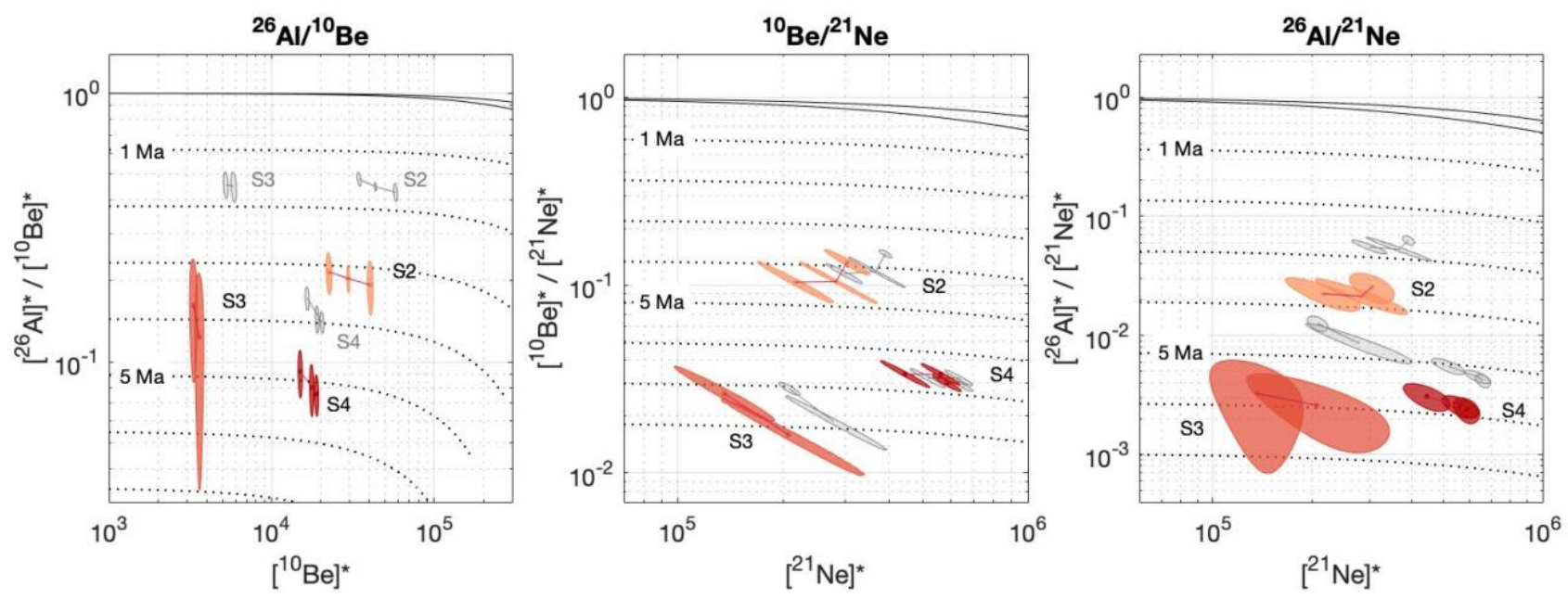

Figure 10 Paired-nuclide diagram for (a) ${ }^{26} \mathrm{Al}-{ }^{10} \mathrm{Be}$, (b) ${ }^{10} \mathrm{Be}-{ }^{21} \mathrm{Ne}$, and (c) ${ }^{26} \mathrm{Al}-{ }^{21} \mathrm{Ne}$ pairs. Solid black lines show the steady-state erosion zone, and dashed lines show the burial lines as Million-year decay isochrons. The nuclide concentration for each data point is represented by a shaded ellipse of its 1-sigma uncertainty. Grey data points show the measured nuclide concentrations for the paleo surface samples as described in Fig. 9d-e. Shaded red data ellipses show the resulting nuclide concentrations when subtracting the modeled nuclide concentration from the measured. The burial age (dashed isochron lines) for which a sample lies represent the apparent burial age and is the maximum single period the sample has been buried since current time. Color shades refer to the different paleo surface units as described in Fig. 7. *Nuclide concentrations normalized to respective surface production rate.

\section{Discussion}

\subsection{Sublimation rate}

The sublimation rate is tightly constrained between $22.77-22.96 \mathrm{~m} \mathrm{Myr}^{-1}$ (Fig. 8b) and independent of the age and erosion rate (Fig. 8d,e). With increasing sublimation rate, a sample having low nuclide concentration at deeper depth (caused by increased shielding mass) approaches the ice surface more rapidly. Having spent less time near the ice surface, a sample found in the top meter of the ice will have a much lower total nuclide concentration than a sample at the lower part of the supraglacial debris. This difference in nuclide concentration between the uppermost ice sample and the bottom supraglacial debris sample allows for the sublimation rate to be well constrained. 
https://doi.org/10.5194/tc-2022-18

Preprint. Discussion started: 2 February 2022

(c) Author(s) 2022. CC BY 4.0 License.

(c) (i)

645

Previous estimates of the sublimation rate in Ong Valley range between 19-22 $\mathrm{m} \mathrm{Myr}^{-1}$ (Bibby et al., 2016), where sublimation rates of buried ice masses determined using cosmogenic nuclides elsewhere in TAM range between $0.7-37 \mathrm{~m}$ $\mathrm{Myr}^{-1}$ (Schäfer et al., 2000; Ng et al., 2005; Morgan et al., 2010b). These rates broadly agree with a sublimation rate of $22.86 \mathrm{~m} \mathrm{Myr}^{-1}$ as reported here in Ong valley. Sublimation rates obtained from modeled water vapor diffusion are order of

650 magnitude higher; 100-500 m Myr-1 (Hindmarsh et al., 1998; Mckay et al., 1998; Kowalewski et al., 2006; Hagedorn et al., 2007; Mckay, 2008; Schorghofer, 2009). Such orders of magnitude higher sublimation rates would suggest a total surface elevation lowering of $\sim 300-1500 \mathrm{~m}$ as compared to our calculated total ice surface lowering of $\sim 68 \mathrm{~m}$ and are inconsistent with glacial moraine elevations and field observations in Ong Valley.

655 The sublimation rate represents an average rate since the ice emplacement $\sim 3 \mathrm{Myr}$ ago. Most likely the sublimation has been decreasing over time as the supraglacial debris thickens (Mackay and Marchant, 2016). However, this relationship is uncertain, and therefore we do not account for it.

\subsection{Erosion rate}

The erosion rate and age of the ice are well constrained within an erosion-age tradeoff (Fig. 8f). For an eroding surface,

660 debris of low nuclide concentrations from below will approach the surface at a rate of erosion. With increased surface erosion rate, an older exposure age is required in order to account for the loss of high surficial nuclide concentrations, leading to an expected erosion-age tradeoff.

The majority of Antarctic studies of subaerial surface erosion rate using cosmogenic nuclides are obtained from boulders and 665 bedrock of various lithologies (Marrero et al., 2018, and references therein). Only a few erosion rates have been determined from surficial regolith (Putkonen et al., 2008; Morgan et al., 2010a; Bibby et al., 2016). While Bibby et al. (2016) found a $0.89 \mathrm{~m} \mathrm{Myr}^{-1}$ for the middle drift, a range between $0.2-2 \mathrm{~m} \mathrm{Myr}^{-1}$ has been observed in McMurdo Dry Valleys (Putkonen et al., 2008; Morgan et al., 2010a). Therefore, an erosion rate of $0.206 \mathrm{~m} \mathrm{Myr}^{-1}$ as reported here for the supraglacial debris is in agreement.

\subsection{Englacial Debris Concentration}

In Ong Valley, we measured an average debris concentration of 0.13 by weight in the ice (Eq. 1) which is in the same range as measurements made in Beacon Valley ( 0.085 by Marchant et al., 2002; and 0.Morgan et al., 2010a). While the modeled debris concentration of 0.035 by weight in the sublimated ice over a span of $2.95 \mathrm{Ma}$ is lower than measured debris 
https://doi.org/10.5194/tc-2022-18

Preprint. Discussion started: 2 February 2022

(c) Author(s) 2022. CC BY 4.0 License.

(c) (i)

concentration of buried ice in Antarctica, it is consistent with the expectation that the debris content increases towards the bottom of glacial ice, due to subglacial entrainment of the debris. Thus, it is expected that the modeled debris concentration for the sublimated ice here results in a lower concentration than measured in the remaining basal ice.

\subsection{Mixing layer}

Predicted cosmogenic nuclide concentrations in the supraglacial debris decreases with depth at a higher rate than measured nuclide concentrations (Fig. 9a-c). This leads to a systematic misfit between observations and model predictions. By either

680 decreasing the sublimation rate, increasing the erosion rate, and/or decreasing the age of ice emplacement, a steeper predicted cosmogenic nuclide depth profile can be obtained for the supraglacial debris. However, neither of these scenarios will result in a better fit for the near-surface pit samples. The difficulty of fitting the forward model to the near-surface pit samples suggests that partial vertical mixing of the supraglacial debris may have occurred.

685 As the supraglacial debris is accumulating due to sublimation, debris having low cosmogenic nuclide concentrations from below will mix with debris of higher surficial cosmogenic nuclide concentrations. Therefore, any (partial or full) vertical mixing of the supraglacial debris would cause a decrease in the cosmogenic nuclides inventory in any above lying sample. Without accounting for any vertical mixing of the supraglacial debris, the model predictions result in an overestimation of the cosmogenic nuclide concentration for the near-surface pit samples and an underestimation of newly accumulating

690 supraglacial debris from the ice surface as observed in Fig. 9a-c. Further, any vertical mixing would decrease the nuclide ratio, which would explain why all paired-nuclide ratios for the supraglacial debris samples plots below the steady state erosion zone (Fig. 9d-f).

It has previously been suggested that no vertical mixing occurs in the supraglacial debris layers in Ong valley (Bibby et al.,

695 2016) and supraglacial debris layers studied in Beacon Valley (Morgan et al., 2010a, b). While the current measured nuclide profile may not reflect a fully mixed zone as seen elsewhere in temperate climate with bioturbation (Perg et al., 2002), a partially mixed supraglacial debris layer is likely the result of active polygon formation found at the surface of the middle drift.

\subsection{Exposure ages from boulders}

700 In general, a boulder having experienced a single period of exposure that is equal to the ice emplacement age of the middle drift should display concordant ${ }^{10} \mathrm{Be}$ and ${ }^{21} \mathrm{Ne}$ ages. However, all measured boulders show apparent ${ }^{10} \mathrm{Be}$ exposure ages younger than that of ${ }^{21} \mathrm{Ne}$ ages (Table 2) and are therefore inconsistent with a simple exposure having negligible erosion. 
https://doi.org/10.5194/tc-2022-18

Preprint. Discussion started: 2 February 2022

(c) Author(s) 2022. CC BY 4.0 License.

(c) (i)

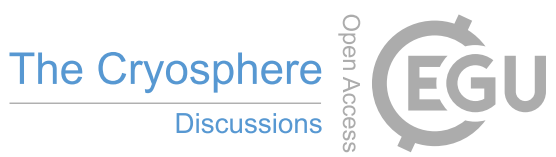

From the ${ }^{10} \mathrm{Be} /{ }^{21} \mathrm{Ne}$ ratio (Fig. 11) it is observed that the surface boulders have experienced erosion while exposed to cosmicrays at the surface as the paired-nuclide ratio lays within the steady-state erosion zone (see details in sect. 3). Three outliers of the east lateral moraine boulders $(214,217$, and 218; Fig. 11a) show neither age or erosion rates that agree with continuous exposure and lie below the steady erosion zone, in a region of intermittent exposure. Thus, these boulders show a complex exposure history having experienced at least one period of burial at some point in time.
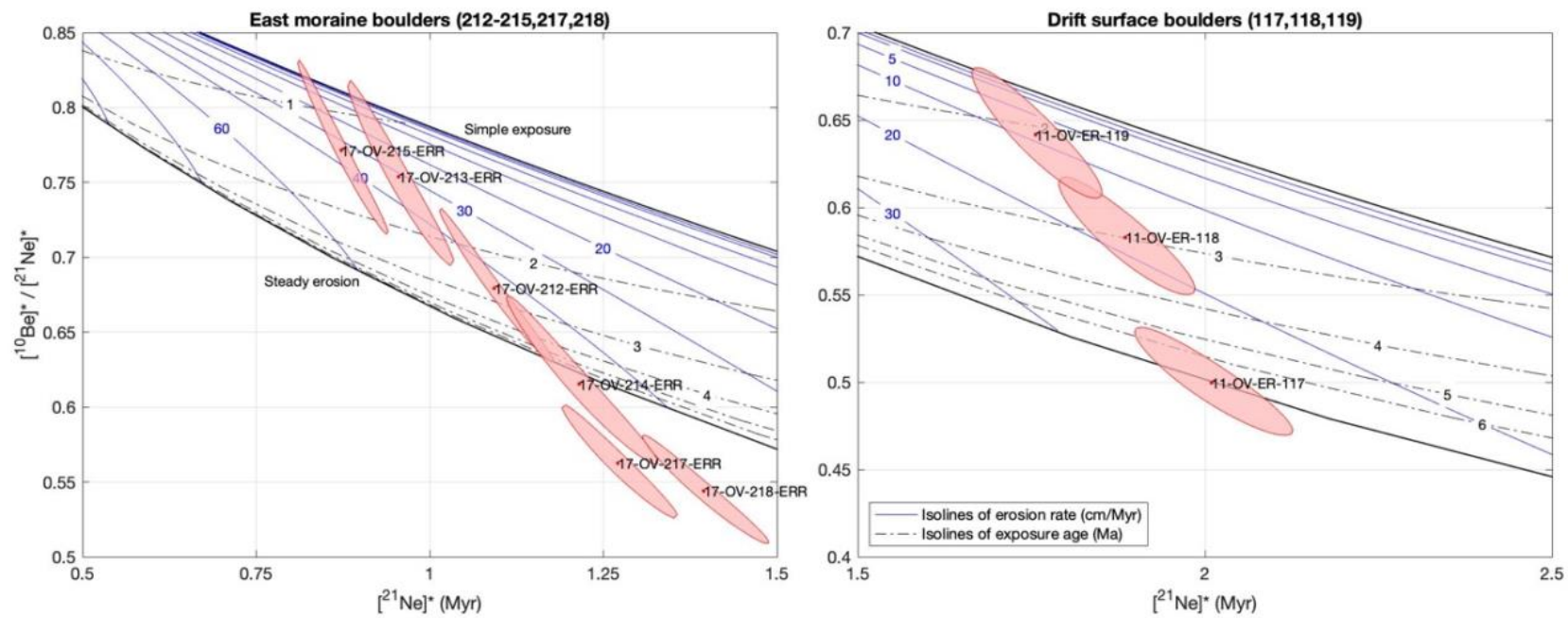

710 Figure $11^{10} \mathrm{Be}-{ }^{21} \mathrm{Ne}$ paired-nuclide diagram of the boulder samples. Black solid lines are the simple exposure line and steady state erosion line, which marks the zone of continuous exposure. Blue lines are isolines of constant steady erosion (cm Myr-1), and black dashed lines are isoline of constant exposure age (Myr). The measured nuclide concentration for each sample is represented by a red dot with red shading of its 1-sigma uncertainty. *Nuclide concentrations normalized to respective surface production rate.

A more realistic exposure age and erosion rate can be determined for boulders having a nuclide ratio within the steady-state

erosion zone. By assuming a single period of continuous exposure at a steady state erosion, we can solve for both the exposure and erosion rate as detailed in Balco et al. (2014). The results of a 10,000-iteration Monte Carlo simulation using this procedure are shown in Fig. 12. Some samples permit infinite ages at a steady erosion rate if the ${ }^{10} \mathrm{Be} /{ }^{21} \mathrm{Ne}$ nuclide ratio lies outside of the continuous exposure zone. Therefore, only samples permitting finite age-erosion rate solutions are shown in Fig. 12. 
https://doi.org/10.5194/tc-2022-18

Preprint. Discussion started: 2 February 2022

(c) Author(s) 2022. CC BY 4.0 License.

(c) (i)
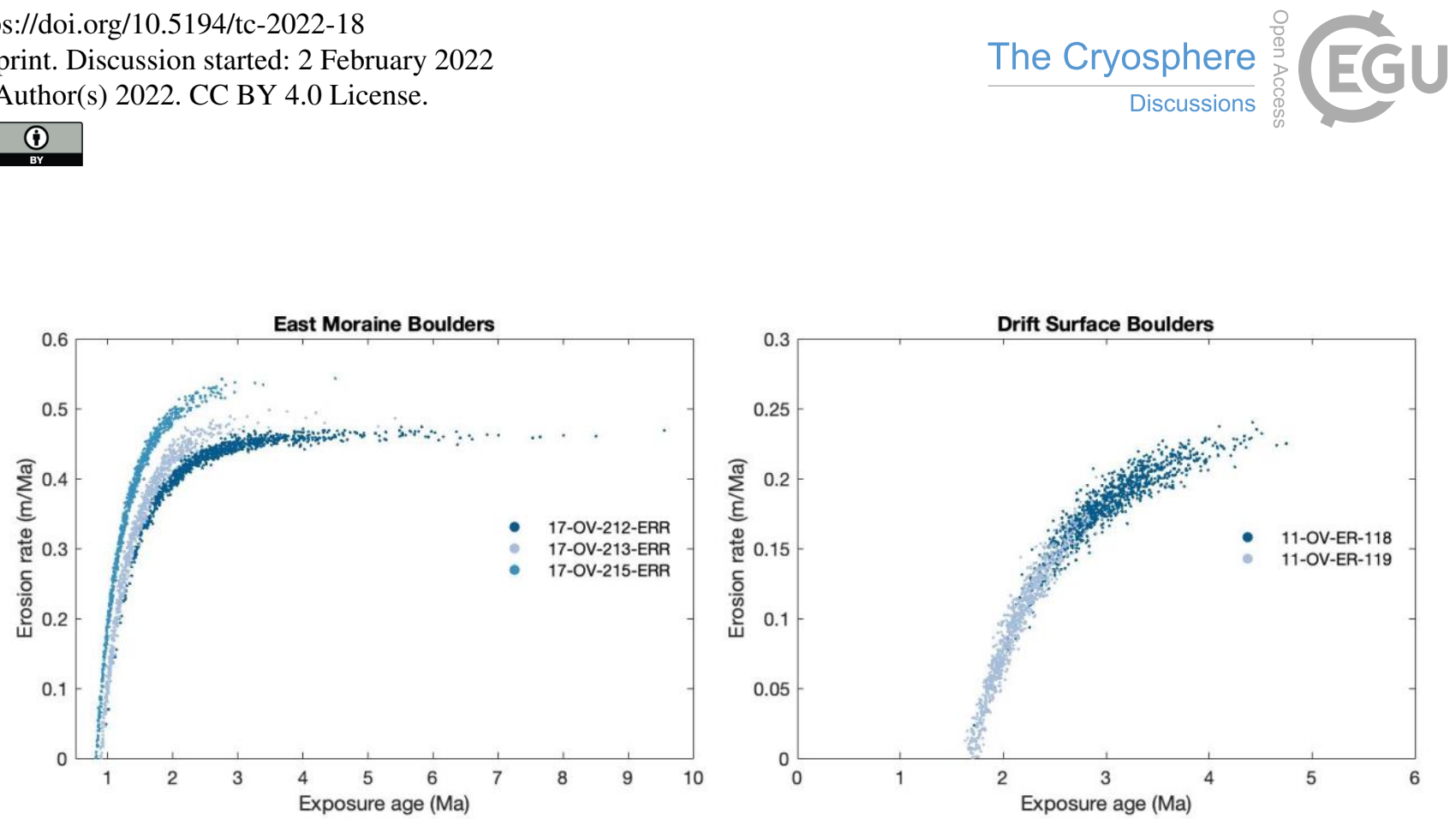

Figure 12 Exposure ages and erosion rates for the middle drift surface and moraine boulders.

The lateral moraine boulders having a finite age-erosion rate solution display a $68 \%$ confidence bound on the age of 1.0 3.9 Ma and erosion rates of $0.20-0.48 \mathrm{~m} \mathrm{Myr}^{-1}$ (Fig. 12a). From field observations, the lateral moraine from which boulder measurements were sampled appears to be a younger recessional moraine and therefore not an indication of a maximum extent for the middle drift, which is observed at higher elevation. These observations would suggest that boulders from this lateral moraine have most likely been disturbed post ice emplacement. Thus, the ${ }^{10} \mathrm{Be}^{21} \mathrm{Ne}$ ratio age for the moraine is more likely to represent a minimum limiting age of ice emplacement (Hallet and Putkonen, 1994; Putkonen and Swanson, 2003).

The middle drift surface boulders have a $68 \%$ confidence bound on the age of 1.8 - $3.5 \mathrm{Ma}$ with erosion rates ranging between $0.05-0.21 \mathrm{~m} \mathrm{Myr}^{-1}$ and therefore agree with our modeled age of $2.96 \mathrm{Ma}$ for the middle drift ice (Fig. 12b). One outlier (11-OV-ER-117) has steady state erosion for a period greater than several half-lives of ${ }^{10} \mathrm{Be}(>\sim 5 \mathrm{Ma})$, and therefore contains no age information. We attribute this increased nuclide concentrations to an extended period of exposure prior to deposition in Ong Valley.

\subsection{Multiple Glacial Events}

735 Samples having a burial age equal to that of the ice emplacement age are considered to have been derived from a paleo surface exposed in Ong Valley during ice advance of the middle ice. After entrainment into the advancing ice, the paleo surface material was immediately buried under a thick layer of ice and shielded from the cosmic-ray flux. 
As mentioned in sect. 6.2, the age of the ice determined from modeled nuclide predictions is constrained such that the ice cannot be older than the minimum burial age obtained from any sample across the three paired-nuclide ratios. We find that the minimum burial age of 3.21 $\pm 0.20 \mathrm{Ma}$ for S2 agrees with the age of the middle ice ( $2.95+0.18 /-0.21 \mathrm{Ma})$. Hence, S2 is likely to have been at the surface during the glacial advance leading to the deposition of the middle ice $\sim 3 \mathrm{Ma}$. S2 is found at depths in between E1 and E2 (Fig. 7), which have no prior exposure history. This would suggest that S2 is not in stratigraphic order and has been mixed up into the ice during advance of the middle ice into Ong Valley.

Both S3 and S4 display older burial ages which are not uniform across the three paired-nuclide ratios (Fig. 10). This suggests that both S3 and S4 have experienced a complex exposure-burial history of prior entrainment which goes beyond the exposure history of the middle drift ice. The estimated burial ages represent the minimum total burial time a sample has experienced, but also the maximum burial time of a single burial event. For S3 and S4, additional burial time is needed beyond the age of the ice (> $2.95 \mathrm{Ma}$ ) and must have experienced multiple periods of burial. The simplest explanation is to assume that during advance of the middle ice, Ong Valley looked similar to today, such that the middle ice advanced over an already existing ice-cored drift unit. Perhaps this is now preserved as the older drift (Fig. 2). If this is the case, then S3 and S4 units presumably are debris that was buried for some time in the older ice, and then buried again in or under the middle ice. We use "in or under" because it is possible that (i) we cored through the middle ice into a stratigraphically underlying mass of older ice. However, it is also possible that (ii) sections of the older ice were entrained during advancement of the middle ice, and we then have a mixture of older and younger ice. The core did not display an obvious stratigraphic boundary. In fact, most of the observed grain in the ice-debris mass is at steep angles and disturbed (Section 4.1.2), which would tend to favor a mixing of the ice hypothesis. Regardless, either is possible and geochemical analysis of the ice could potentially help resolve this.

The uncertainty associated with the age of this older, separate, underlying ice mass is greater compared to the middle ice due to the complexity associated with the exposure-burial dating. That is, the burial age obtained here is the apparent burial of a single event. However, a sample could have experienced multiple shorter periods of exposure-burial events which are not accounted for. We therefore only report an estimate with minimum and maximum constraints. A sample that experiences a single period of exposure at the surface have nuclide concentration ratio dependent on the duration of exposure. When buried to a depth where nuclide production is significantly reduced, the change in ratio is primarily dependent on the radioactive decay associated with the duration of burial. Therefore, when solving for the burial age for each of these paleosurface units, we can also solve for the exposure age that has occurred prior to burial by the middle ice (Balco and Rovey, 2008). 
With S2 representing a surface sample from a supraglacial debris prior to deposition of the middle ice, we find the surface exposure age of $\mathrm{S} 2$ to be $0.163 \pm 0.058 \mathrm{Ma}, 0.268 \pm 0.046 \mathrm{Ma}$, and $0.268 \pm 0.046 \mathrm{Ma}$ for the paired-nuclide ratios, ${ }^{26} \mathrm{Al} /{ }^{10} \mathrm{Be}$, ${ }^{10} \mathrm{Be} /{ }^{21} \mathrm{Ne}$, and ${ }^{26} \mathrm{Al} /{ }^{21} \mathrm{Ne}$ respectively. This suggests that the age of an underlying ice mass is at least that of the minimum burial age plus the exposure age for S2. On the contrary, the age of the ice in which a sample is embedded cannot be older than the burial age of a given sample. Then, the maximum burial age across the three paleo surfaces S2-4 for any of the paired-nuclide ratios must serve as the upper bound for the age. Therefore, there is no scenario in which this separate, older underlying ice mass can be younger than 3.3 Myr or older than 7.6 Myr. However, a more likely age for this older deposit would be $4.3-5.1 \mathrm{Ma}$ which is the burial age obtained from the ${ }^{26} \mathrm{Al} /{ }^{10} \mathrm{Be}$ ratio for $\mathrm{S} 3$ and $\mathrm{S} 4$, as it is unclear whether or not S3 and S4 are the same or different units.

780 It is difficult to determine whether or not there is any defined boundary between the older and younger ice masses. With an increase of nuclide concentrations downcore and, in addition, that samples from E2, S3, and S4 appear to form mixing arrays in the two-nuclide diagrams shown in Fig. 9, it appears likely that S3 is a mixture of a high-nuclide-concentration end member, which may be represented by S4, and a low-nuclide-concentration end member represented by E2. However, a boundary or transition most likely exists between E2 and S4.

\section{$785 \quad 7.7$ Antarctica during the Pliocene}

The ages reported here coincide with the Pliocene Epoch (5.3 - 2.6 Ma). Research on Pliocene climate and how it affected the Antarctic ice sheet has gained much attention as a likely analog for modern anthropogenic warming (Dolan et al., 2018). During the Pliocene epoch there is evidence of prominent glacial deposits, in which two are identified in the southern hemisphere as globally recognizable glaciations (summarized in De Schepper et al., 2014); one occurring during the early 790 Pliocene (ca. 4.9-4.8 Ma), and another during the Late Pliocene (ca. 3.3 Ma), also identified as the Marine Isotope Stage (MIS) M2 glaciation. The latter is followed by a warmer-than present mid-Piacenzian Warming Period (mPWP; 3.3-3.0 Ma)(Haywood et al., 2013; De Schepper et al., 2014; Dowsett et al., 2016). This warming period ends by a Late Pliocene cooling, post $\sim 3 \mathrm{Ma}$, leading to a global glaciation around the Pliocene-Pleistocene boundary (De Schepper et al., 2014).

795 Because the uncertainty of the ice emplacement age $( \pm 0.2 \mathrm{Ma})$ exceeds both the $40 \mathrm{kyr}$ and $100 \mathrm{kyr}$ climate cycles of the Pliocene epoch (Caballero-Gill et al., 2019), we are not able to accurately relate the deposition of the middle ice to an individual glacial event. Furthermore, the age of $2.95+0.18 /-0.22$ Ma for the middle ice emplacement, which requires an East Antarctic Ice Sheet (EAIS) elevation greater than $200 \mathrm{~m}$ above present, cannot confidently be assigned to either the warmer period prior to $3 \mathrm{Ma}$ or the cooler period post 3 Ma. Balter-Kennedy et al. (2020) concluded that glacial deposits 
https://doi.org/10.5194/tc-2022-18

Preprint. Discussion started: 2 February 2022

(c) Author(s) 2022. CC BY 4.0 License.

(c) (i)

800 recording a higher than present EAIS elevation at Roberts Massif, a nearby location in the Transantarctic Mountains, most likely postdated the mPWP. Therefore, if the ice advance in Ong Valley were correlative with that at Roberts Massif, it would also be associated with the 3 Ma cooling. However, this is speculative.

The oldest englacial debris that we have dated in Ong Valley is dated at 4.3-5.1 Myrs old. Although the dated age range is

805 rather wide due to complexities resulting from old age and exposure-burial dating, it is still direct evidence of an EAIS expansion and local ice expansion during that time. This dated age suggests that the ice sheet expansion predated the MIS M2 cooling event and possibly coincided with the Early Pliocene global glaciation (ca. 4.9 - 4.8 Ma). If in fact the older ice is still present below the middle ice mass, then it did not melt during a period of warming. Thus, additional evidence indicating whether or not two ice units are present would be important in understanding the climate during the Pliocene

810 Epoch. Since 3 Myrs ago there has never been a comparable ice sheet expansion in Ong Valley as was seen in early/mid and late Pliocene. The only notable, but small ice sheet advance or stagnation evident in Ong Valley is the youngest drift dated at 11-13 kyrs.

\section{Conclusions}

Glacial ice is a well-known paleo climate archive. Great efforts have been made to find ice older than 1 Ma since the paucity 815 of ice beyond million years of age creates uncertainties for future climate predictions. In Ong Valley, Antarctica, the middle drift harbors a large ice mass buried $62 \mathrm{~cm}$ below the surface of supraglacial debris. We collected a $944 \mathrm{~cm}$ long ice core and measured concentrations of the cosmic-ray produced nuclides ${ }^{10} \mathrm{Be},{ }^{26} \mathrm{Al}$, and ${ }^{21} \mathrm{Ne}$ from the englacial debris and samples from the supraglacial debris directly above it. We developed a numerical forward model which predicts the accumulation of cosmogenic nuclides in the englacial debris and the above laying supraglacial debris during a single event of exposure,

820 constrained by sublimation, surface erosion and accumulation of supraglacial debris. The modeled nuclide concentrations are then fitted to the measured nuclide concentrations in the ice core.

Downcore increase in measured nuclide concentrations suggest that sections of englacial debris consist of both subglacially entrained debris and recycled paleo surfaces having a complex exposure-burial history prior to entrainment. This allows us to 825 apply a combination of exposure- and burial-dating to the forward model. We find the age of the middle drift ice mass to be $2.95 \mathrm{Ma}$, with a constant ice sublimation rate of $22.86 \mathrm{~m} \mathrm{Myr}^{-1}$ and surface erosion rate of $0.206 \mathrm{~m} \mathrm{Myr}^{-1}$. Cosmogenic nuclide exposure dating of surface boulders belonging to the surface of the coring site are consistent with the modeled age of $\sim 3 \mathrm{Ma}$ for the ice emplacement. 
https://doi.org/10.5194/tc-2022-18

Preprint. Discussion started: 2 February 2022

(c) Author(s) 2022. CC BY 4.0 License.

(c) (i)

830 Exposure-burial dating on the englacial paleo surface debris reveals that the lower section of the ice core belongs to a separate and older deposit, emplaced 4.3 - 5.1 Myr ago. We interpret this lower section as a portion of an older ice mass either in situ or transported during emplacement of the younger ice. The ages of the two separate ice masses found below the middle drift can be directly related to glacial advances. These findings provide direct evidence of an Antarctic ice sheet that was larger than present during the early and late Pliocene epoch.

Furthermore, we show that exposure-burial dating of cosmogenic nuclides measured in situ in basal ice debris layers can be used for age constraint of past ice advance. Specifically, we have debris layers in one ice core that suggest three different burial ages, where at least two of them are dated to be older than the age of the ice itself. This is important for understanding in situ cosmogenic-nuclide data from out of context subglacial sediment.

Collectively our results show that the continental ice sheet advanced into Ong Valley repeatedly and evidence of at least two of such advances at 2.95 Ma, and 4.3-5.1 Ma are still preserved in lateral moraines, drifts, and stacked ice masses. Since 2.95 Myrs ago the only evidence of ice advance or stagnation in the Ong Valley was $\sim 10$ kyrs ago.

\section{Code availability}

845 MATLAB code used for forward modeling and model fitting calculations is available at https://github.com/balcs/ong-valleyOD1-model.

\section{Data availability}

All data described in the paper are included in the Supplement.

\section{Author contributions}

$850 \mathrm{MB}, \mathrm{JP}, \mathrm{GB}$, and DM conducted field work and sample collection. MB, LBC, GB, and DM carried out cosmogenic nuclide measurements and were responsible for data reduction. GB and MB developed the model for analysis. MB prepared the manuscript with contributions from all authors. 
https://doi.org/10.5194/tc-2022-18

Preprint. Discussion started: 2 February 2022

(c) Author(s) 2022. CC BY 4.0 License.

(c) (i)

\section{Competing interests}

The authors declare that they have no conflict of interest.

\section{Acknowledgements}

This work would not have been possible without the efforts of many U.S. Antarctic Program personnel at McMurdo Station, Shackleton Glacier Camp, and elsewhere, as well as pilots and ground crew of the New York Air National Guard, Kenn Borek Air, and PHI, Inc. Development, deployment, and operation of the Winkie Drill was made possible by the US Ice Drilling Program, in particular Grant Boeckmann. Andrew Grant assisted with field work in Ong Valley, and Alan Hidy of 860 the Center for Accelerator Mass Spectrometry, Lawrence Livermore National Laboratory, assisted with AMS isotope ratio measurements and beryllium extraction chemistry. Satellite imagery in figure $1 \mathrm{~b}$ was provided by the Polar Geospatial Center under NSF-OPP awards 1445205, 1445168, and 1445169.

\section{Financial Support}

This project was supported by the U.S. National Science Foundation via grants OPP- 1445205, OPP- 1445168, and OPP-

865 1445169. In addition, Balco's work on this project was partially supported by the Ann and Gordon Getty Foundation. The University of Vermont Community Cosmogenic Facility is supported by the U.S. National Science Foundation via grant number EAR-1735676.

\section{References}

Balco, G.: Production rate calculations for cosmic-ray-muon-produced 10Be and 26Al benchmarked against geological calibration data, Quaternary Geochronology, 39, 150-173, 10.1016/j.quageo.2017.02.001, 2017.

Balco, G. and Rovey, C. W.: An isochron method for cosmogenic-nuclide dating of buried soils and sediments, American Journal of Science, 308, 1083-1114, 10.2475/10.2008.02, 2008.

Balco, G. and Shuster, D. L.: Production rate of cosmogenic $21 \mathrm{Ne}$ in quartz estimated from 10Be, 26Al, and $21 \mathrm{Ne}$ concentrations in slowly eroding Antarctic bedrock surfaces, Earth and Planetary Science Letters, 281, 48-58, 875 10.1016/j.eps1.2009.02.006, 2009.

Balco, G., Stone, J. O., Lifton, N. A., and Dunai, T. J.: A complete and easily accessible means of calculating surface exposure ages or erosion rates from $10 \mathrm{Be}$ and $26 \mathrm{Al}$ measurements, Quaternary Geochronology, 3, 174-195, 10.1016/j.quageo.2007.12.001, 2008. 
https://doi.org/10.5194/tc-2022-18

Preprint. Discussion started: 2 February 2022

(c) Author(s) 2022. CC BY 4.0 License.

(c) (i)

Balco, G., Stone, J. O. H., Sliwinski, M. G., and Todd, C.: Features of the glacial history of the Transantarctic Mountains

inferred from cosmogenic 26Al, 10Be and 21Ne concentrations in bedrock surfaces, Antarctic Science, 26, 708-723, 10.1017/s0954102014000261, 2014.

Balco, G., Blard, P.-H., Shuster, D. L., Stone, J. O. H., and Zimmermann, L.: Cosmogenic and nucleogenic 21Ne in quartz in a 28-meter sandstone core from the McMurdo Dry Valleys, Antarctica, Quaternary Geochronology, 52, 63-76, 10.1016/j.quageo.2019.02.006, 2019.

Balter-Kennedy, A., Bromley, G., Balco, G., Thomas, H., and Jackson, M. S.: A 14.5-million-year record of East Antarctic Ice Sheet fluctuations from the central Transantarctic Mountains, constrained with cosmogenic $3 \mathrm{He}, 10 \mathrm{Be}, 21 \mathrm{Ne}$, and 26Al, The Cryosphere, 14, 2647-2672, 10.5194/tc-14-2647-2020, 2020.

Barrett, P. J., Lindsay, J. F., and Gunner, J.: Reconnaissance geologic map of the Mount Rabot quadrangle, Transantarctic Mountains, Antarctica., 10.3133/a1, 1970.

890 Bibby, T., Putkonen, J., Morgan, D., Balco, G., and Shuster, D. L.: Million year old ice found under meter thick debris layer in Antarctica, Geophysical Research Letters, 43, 6995-7001, 10.1002/2016gl069889, 2016.

Boeckmann, G. V., Gibson, C. J., Kuhl, T. W., Moravec, E., Johnson, J. A., Meulemans, Z., and Slawny, K.: Adaptation of the Winkie Drill for subglacial bedrock sampling, Annals of Glaciology, 62, 109-117, 10.1017/aog.2020.73, 2020.

Borchers, B., Marrero, S., Balco, G., Caffee, M., Goehring, B., Lifton, N., Nishiizumi, K., Phillips, F., Schaefer, J., and

895 Stone, J.: Geological calibration of spallation production rates in the CRONUS-Earth project, Quaternary Geochronology, 31, 188-198, 10.1016/j.quageo.2015.01.009, 2016.

Braucher, R., Del Castillo, P., Siame, L., Hidy, A. J., and Bourlés, D. L.: Determination of both exposure time and denudation rate from an in situ-produced 10Be depth profile: A mathematical proof of uniqueness. Model sensitivity and applications to natural cases, Quaternary Geochronology, 4, 56-67, 10.1016/j.quageo.2008.06.001, 2009.

900 Bulthuis, K., Arnst, M., Sun, S., and Pattyn, F.: Uncertainty quantification of the multi-centennial response of the Antarctic ice sheet to climate change, The Cryosphere, 13, 1349-1380, 10.5194/tc-13-1349-2019, 2019.

Caballero-Gill, R. P., Herbert, T. D., and Dowsett, H. J.: 100-kyr Paced Climate Change in the Pliocene Warm Period, Southwest Pacific, Paleoceanography and Paleoclimatology, 34, 524-545, 10.1029/2018pa003496, 2019.

Castellano, E., Becagli, S., Jouzel, J., Migliori, A., Severi, M., Steffensen, J. P., Traversi, R., and Udisti, R.: Volcanic

eruption frequency over the last $45 \mathrm{ky}$ as recorded in Epica-Dome $\mathrm{C}$ ice core (East Antarctica) and its relationship with climatic changes, Global and Planetary Change, 42, 195-205, 10.1016/j.gloplacha.2003.11.007, 2004.

Corbett, L. B., Bierman, P. R., and Rood, D. H.: An approach for optimizing in situ cosmogenic 10Be sample preparation, Quaternary Geochronology, 33, 24-34, 10.1016/j.quageo.2016.02.001, 2016. 
https://doi.org/10.5194/tc-2022-18

Preprint. Discussion started: 2 February 2022

(c) Author(s) 2022. CC BY 4.0 License.

(c) (i)

Dansgaard, W., Johnsen, S. J., Moller, J., and Langway, C. C., Jr.: One thousand centuries of climatic record from camp century on the greenland ice sheet, Science, 166, 377-380, 10.1126/science.166.3903.377, 1969.

De Schepper, S., Gibbard, P. L., Salzmann, U., and Ehlers, J.: A global synthesis of the marine and terrestrial evidence for glaciation during the Pliocene Epoch, Earth-Science Reviews, 135, 83-102, 10.1016/j.earscirev.2014.04.003, 2014.

Dolan, A. M., de Boer, B., Bernales, J., Hill, D. J., and Haywood, A. M.: High climate model dependency of Pliocene Antarctic ice-sheet predictions, Nat Commun, 9, 2799, 10.1038/s41467-018-05179-4, 2018.

Dowsett, H., Dolan, A., Rowley, D., Moucha, R., Forte, A. M., Mitrovica, J. X., Pound, M., Salzmann, U., Robinson, M., Chandler, M., Foley, K., and Haywood, A.: The PRISM4 (mid-Piacenzian) paleoenvironmental reconstruction, Climate of the Past, 12, 1519-1538, 10.5194/cp-12-1519-2016, 2016.

Dunai, T. J.: Cosmogenic Nuclides: Principles, Concepts and Applications in the Earth Surface Sciences, Cambridge University Press, Cambridge, DOI: 10.1017/CBO9780511804519, 2010.

Edwards, K. L., Padilla, A. J., Evans, A., Morgan, D., Balco, G., Putkonen, J., and Bibby, T.: Provenance of glacial tills in Ong Valley, Antarctica, inferred from quartz cathodoluminescence imaging, zircon $\mathrm{U} / \mathrm{Pb}$ dating, and trace element geochemistry, American Geophysical Union, Fall Meeting 2014, San Francisco, Calif.2014.

Fischer, H., Severinghaus, J., Brook, E., Wolff, E., Albert, M., Alemany, O., Arthern, R., Bentley, C., Blankenship, D., Chappellaz, J., Creyts, T., Dahl-Jensen, D., Dinn, M., Frezzotti, M., Fujita, S., Gallee, H., Hindmarsh, R., Hudspeth, D., Jugie, G., Kawamura, K., Lipenkov, V., Miller, H., Mulvaney, R., Parrenin, F., Pattyn, F., Ritz, C., Schwander, J., Steinhage, D., Van Ommen, T., and Wilhelms, F.: Where to find 1.5 million yr old ice for the IPICS "Oldest-Ice" ice core, Climate of the Past, 9, 2489-2505, 10.5194/cp-9-2489-2013, 2013.

Fredskild, B. and Wagner, P.: Pollen and fragments of plant tissue in core samples from the Greenland Ice Cap, Boreas, 3, 105-108, 10.1111/j.1502-3885.1974.tb00668.x, 1974.

930 Hagedorn, B., Sletten, R. S., and Hallet, B.: Sublimation and ice condensation in hyperarid soils: Modeling results using field data from Victoria Valley, Antarctica, Journal of Geophysical Research, 112, 10.1029/2006jf000580, 2007.

Hallet, B. and Putkonen, J.: Surface dating of dynamic landforms: young boulders on aging moraines, Science, 265, 937940, 10.1126/science.265.5174.937, 1994.

Haywood, A. M., Chandler, M. A., Valdes, P. J., Salzmann, U., Lunt, D. J., and Dowsett, H. J.: Comparison of mid-Pliocene climate predictions produced by the HadAM3 and GCMAM3 General Circulation Models, Global and Planetary Change, 66, 208-224, 10.1016/j.gloplacha.2008.12.014, 2009.

Haywood, A. M., Hill, D. J., Dolan, A. M., Otto-Bliesner, B. L., Bragg, F., Chan, W. L., Chandler, M. A., Contoux, C., Dowsett, H. J., Jost, A., Kamae, Y., Lohmann, G., Lunt, D. J., Abe-Ouchi, A., Pickering, S. J., Ramstein, G., Rosenbloom, 
https://doi.org/10.5194/tc-2022-18

Preprint. Discussion started: 2 February 2022

(c) Author(s) 2022. CC BY 4.0 License.

(c) (i)

N. A., Salzmann, U., Sohl, L., Stepanek, C., Ueda, H., Yan, Q., and Zhang, Z.: Large-scale features of Pliocene climate:

results from the Pliocene Model Intercomparison Project, Climate of the Past, 9, 191-209, 10.5194/cp-9-191-2013, 2013.

Heisinger, B., Lal, D., Jull, A. J. T., Kubik, P., Ivy-Ochs, S., Knie, K., and Nolte, E.: Production of selected cosmogenic radionuclides by muons: 2. Capture of negative muons, Earth and Planetary Science Letters, 200, 357-369, 10.1016/S0012$821 \mathrm{x}(02) 00641-6,2002 \mathrm{a}$.

Heisinger, B., Lal, D., Jull, A. J. T., Kubik, P., Ivy-Ochs, S., Neumaier, S., Knie, K., Lazarev, V., and Nolte, E.: Production

of selected cosmogenic radionuclides by muons 1. Fast muons, Earth and Planetary Science Letters, 200, 345-355, 10.1016/S0012-821x(02)00640-4, 2002b.

Hidy, A. J., Gosse, J. C., Pederson, J. L., Mattern, J. P., and Finkel, R. C.: A geologically constrained Monte Carlo approach to modeling exposure ages from profiles of cosmogenic nuclides: An example from Lees Ferry, Arizona, Geochemistry Geophysics Geosystems, 11, 10.1029/2010gc003084, 2010.

Hindmarsh, R. C. A., Van der Wateren, F. M., and Verbers, A. L. L. M.: Sublimation of ice through sediment in Beacon Valley, Antarctica, Geografiska Annaler Series a-Physical Geography, 80a, 209-219, DOI 10.1111/j.04353676.1998.00038.x, 1998.

Howat, I. M., Porter, C., Smith, B. E., Noh, M.-J., and Morin, P.: The Reference Elevation Model of Antarctica, The Cryosphere, 13, 665-674, 10.5194/tc-13-665-2019, 2019.

955 Jouzel, J., Masson-Delmotte, V., Cattani, O., Dreyfus, G., Falourd, S., Hoffmann, G., Minster, B., Nouet, J., Barnola, J. M., Chappellaz, J., Fischer, H., Gallet, J. C., Johnsen, S., Leuenberger, M., Loulergue, L., Luethi, D., Oerter, H., Parrenin, F., Raisbeck, G., Raynaud, D., Schilt, A., Schwander, J., Selmo, E., Souchez, R., Spahni, R., Stauffer, B., Steffensen, J. P., Stenni, B., Stocker, T. F., Tison, J. L., Werner, M., and Wolff, E. W.: Orbital and millennial Antarctic climate variability over the past 800,000 years, Science, 317, 793-796, 10.1126/science.1141038, 2007.

960 Kowalewski, D. E., Marchant, D. R., Levy, J. S., and Head, J. W.: Quantifying low rates of summertime sublimation for buried glacier ice in Beacon Valley, Antarctica, Antarctic Science, 18, 421-428, 10.1017/s0954102006000460, 2006.

Lal, D.: Cosmic ray labeling of erosion surfaces in situ nuclide production rates and erosion models, Earth and Planetary Science Letters, 104, 424-439, 10.1016/0012-821X(91)90220-C, 1991.

Lifton, N., Sato, T., and Dunai, T. J.: Scaling in situ cosmogenic nuclide production rates using analytical approximations to atmospheric cosmic-ray fluxes, Earth and Planetary Science Letters, 386, 149-160, 10.1016/j.eps1.2013.10.052, 2014.

Mackay, S. L. and Marchant, D. R.: Dating buried glacier ice using cosmogenic $3 \mathrm{He}$ in surface clasts: Theory and application to Mullins Glacier, Antarctica, Quaternary Science Reviews, 140, 75-100, 10.1016/j.quascirev.2016.03.013, 2016. 
https://doi.org/10.5194/tc-2022-18

Preprint. Discussion started: 2 February 2022

(c) Author(s) 2022. CC BY 4.0 License.

(c) (i)

Marchant, D. R., Lewis, A. R., Phillips, W. M., Moore, E. J., Souchez, R. A., Denton, G. H., Sugden, D. E., Potter Jr, N., and

Landis, G. P.: Formation of patterned ground and sublimation till over Miocene glacier ice in Beacon Valley, southern

Victoria Land, Antarctica, Geological Society of America Bulletin, 114, 718-730, 10.1130/00167606(2002)114<0718:Fopgas>2.0.Co;2, 2002.

Marrero, S. M., Hein, A. S., Naylor, M., Attal, M., Shanks, R., Winter, K., Woodward, J., Dunning, S., Westoby, M., and Sugden, D.: Controls on subaerial erosion rates in Antarctica, Earth and Planetary Science Letters, 501, 56-66, 975 10.1016/j.epsl.2018.08.018, 2018.

Mayewski, P. A.: Glacial geology and late Cenozoic history of the Transantarctic Mountains, Antarctica, Institute of Polar Studies, The Ohio State University, 168, 1975.

McKay, C., Mellon, M. T., and Friedmann, E. I.: Soil temperatures and stability of ice-cemented ground in the McMurdo Dry Valleys, Antarctica, Antarct Sci, 10, 31-38, 10.1017/s0954102098000054, 1998.

980 McKay, C. P.: Snow recurrence sets the depth of dry permafrost at high elevations in the McMurdo Dry Valleys of Antarctica, Antarctic Science, 21, 89-94, 10.1017/s0954102008001508, 2008.

Morgan, D., Putkonen, J., Balco, G., and Stone, J.: Degradation of glacial deposits quantified with cosmogenic nuclides, Quartermain Mountains, Antarctica, Earth Surface Processes and Landforms, 36, 217-228, 10.1002/esp.2039, 2010a.

Morgan, D., Putkonen, J., Balco, G., and Stone, J.: Quantifying regolith erosion rates with cosmogenic nuclides 10Be and 985 26Al in the McMurdo Dry Valleys, Antarctica, Journal of Geophysical Research, 115, 10.1029/2009jf001443, 2010b.

Morgan, D., Miller, E. M., Miranda, E. J., Edwards, K. L., Liu, J. D., Cribb, W., Bergelin, M., Putkonen, J., and Balco, G.: Consistent flow patterns of the Argosy glacier determined from the provenance of glacial till in Ong Valley, Antarctica., GSA 2020 Connect Online, Online2020.

Ng, F., Hallet, B., Sletten, R. S., and Stone, J. O.: Fast-growing till over ancient ice in Beacon Valley, Antarctica, Geology, $990 \quad 33,10.1130 / \mathrm{g} 21064.1,2005$.

Nishiizumi, K.: Preparation of 26Al AMS standards, Nuclear Instruments and Methods in Physics Research Section B: Beam Interactions with Materials and Atoms, 223-224, 388-392, 10.1016/j.nimb.2004.04.075, 2004.

Nishiizumi, K., Imamura, M., Caffee, M. W., Southon, J. R., Finkel, R. C., and McAninch, J.: Absolute calibration of 10Be AMS standards, Nuclear Instruments and Methods in Physics Research Section B: Beam Interactions with Materials and 995 Atoms, 258, 403-413, 10.1016/j.nimb.2007.01.297, 2007.

Nishiizumi, K., Kohl, C. P., Arnold, J. R., Dorn, R., Klein, I., Fink, D., Middleton, R., and Lal, D.: Role of in situ cosmogenic nuclides $10 \mathrm{Be}$ and $26 \mathrm{Al}$ in the study of diverse geomorphic processes, Earth Surface Processes and Landforms, 18, 407-425, 10.1002/esp.3290180504, 1993. 
https://doi.org/10.5194/tc-2022-18

Preprint. Discussion started: 2 February 2022

(c) Author(s) 2022. CC BY 4.0 License.

(c) (i)

Noble, T. L., Rohling, E. J., Aitken, A. R. A., Bostock, H. C., Chase, Z., Gomez, N., Jong, L. M., King, M. A., Mackintosh,

A. N., McCormack, F. S., McKay, R. M., Menviel, L., Phipps, S. J., Weber, M. E., Fogwill, C. J., Gayen, B., Golledge, N. R., Gwyther, D. E., Hogg, A. M., Martos, Y. M., Pena-Molino, B., Roberts, J., Flierdt, T., and Williams, T.: The Sensitivity of the Antarctic Ice Sheet to a Changing Climate: Past, Present, and Future, Reviews of Geophysics, 58, 10.1029/2019rg000663, 2020.

Pagani, M., Liu, Z., Lariviere, J., and Ravelo, A. C.: High Earth-system climate sensitivity determined from Pliocene carbon dioxide concentrations, Nature Geoscience, 3, 27-30, 10.1038/ngeo724, 2010.

Perg, L. A., Anderson, R. S., and Finkel, R. C.: Use of a new 10.Be and $26 \mathrm{Al}$ inventory method to date marine terraces, Santa Cruz, California, USA Comme, Geology, 30, 1147-1148, 10.1130/0091-7613(2002)030<1147:UOANBA>2.0.CO;2, 2002.

Putkonen, J. and Swanson, T.: Accuracy of cosmogenic ages for moraines, Quaternary Research, 59, 255-261, 1010 10.1016/s0033-5894(03)00006-1, 2003.

Putkonen, J., Balco, G., and Morgan, D.: Slow regolith degradation without creep determined by cosmogenic nuclide measurements in Arena Valley, Antarctica, Quaternary Research, 69, 242-249, 10.1016/j.yqres.2007.12.004, 2008.

Sams, S. E.: Applications of Cosmogenic 21Ne Dating to Glacial Deposits in Antarctica and California, Vanderbilt University, 2016.

1015 Scarrow, J. W., Balks, M. R., and Almond, P. C.: Three soil chronosequences in recessional glacial deposits near the polar plateau, in the Central Transantarctic Mountains, Antarctica, Antarctic Science, 26, 573-583, 10.1017/s0954102014000078, 2014.

Schäfer, J. M., Baur, H., Denton, G. H., Ivy-Ochs, S., Marchant, D. R., Schlüchter, C., and Wieler, R.: The oldest ice on Earth in Beacon Valley, Antarctica: new evidence from surface exposure dating, Earth and Planetary Science Letters, 179, 1020 91-99, 10.1016/s0012-821x(00)00095-9, 2000.

Schorghofer, N.: Buffering of sublimation loss of subsurface ice by percolating snowmelt: a theoretical analysis, Permafrost and Periglacial Processes, 20, 309-313, 10.1002/ppp.646, 2009.

Seki, O., Foster, G. L., Schmidt, D. N., Mackensen, A., Kawamura, K., and Pancost, R. D.: Alkenone and boron-based Pliocene pCO2 records, Earth and Planetary Science Letters, 292, 201-211, 10.1016/j.eps1.2010.01.037, 2010.

1025 Stone, J.: Extraction of Al and Be from quartz for isotopic analysis, UW Cosmogenic Nuclide Lab Methods and Procedures, $1-8,2004$.

Stone, J., Sletten, R. S., and Hallet, B.: Old ice, going fast: Cosmogenic isotope measurements on ice beneath the floor of Beacon Valley, Antarctica, Eos Transactions AGU Fall meeting supplement, 81, 2000. 
https://doi.org/10.5194/tc-2022-18

Preprint. Discussion started: 2 February 2022

(c) Author(s) 2022. CC BY 4.0 License.

(c) (1)

Stone, J. O. H., Evans, J. M., Fifield, L. K., Allan, G. L., and Cresswell, R. G.: Cosmogenic Chlorine-36 Production in 1030 Calcite by Muons, Geochimica et Cosmochimica Acta, 62, 433-454, 10.1016/s0016-7037(97)00369-4, 1998.

Sugden, D. E., Marchant, D. R., Potter, N., Souchez, R. A., Denton, G. H., Swisher, C. C., and Tison, J. L.: Preservation of Miocene Glacier Ice in East Antarctica, Nature, 376, 412-414, 10.1038/376412a0, 1995.

Van der Wateren, D. and Hindmarsh, R.: Stabilists strike again, Nature, 376, 10.1038/376389a0, 1995.

Vermeesch, P., Balco, G., Blard, P.-H., Dunai, T. J., Kober, F., Niedermann, S., Shuster, D. L., Strasky, S., Stuart, F. M., 1035 Wieler, R., and Zimmermann, L.: Interlaboratory comparison of cosmogenic 21Ne in quartz, Quaternary Geochronology, 26, 20-28, 10.1016/j.quageo.2012.11.009, 2015.

Willerslev, E., Cappellini, E., Boomsma, W., Nielsen, R., Hebsgaard, M. B., Brand, T. B., Hofreiter, M., Bunce, M., Poinar, H. N., Dahl-Jensen, D., Johnsen, S., Steffensen, J. P., Bennike, O., Schwenninger, J. L., Nathan, R., Armitage, S., de Hoog, C. J., Alfimov, V., Christl, M., Beer, J., Muscheler, R., Barker, J., Sharp, M., Penkman, K. E., Haile, J., Taberlet, P., Gilbert, 1040 M. T., Casoli, A., Campani, E., and Collins, M. J.: Ancient biomolecules from deep ice cores reveal a forested southern Greenland, Science, 317, 111-114, 10.1126/science.1141758, 2007.

Yan, Y., Bender, M. L., Brook, E. J., Clifford, H. M., Kemeny, P. C., Kurbatov, A. V., Mackay, S., Mayewski, P. A., Ng, J., Severinghaus, J. P., and Higgins, J. A.: Two-million-year-old snapshots of atmospheric gases from Antarctic ice, Nature, 574, 663-666, 10.1038/s41586-019-1692-3, 2019. 